\title{
An Extended Genetic Linkage Map for Watermelon Based on a Testcross and a $\mathrm{BC}_{2} \mathrm{~F}_{2}$ Population
}

\author{
Amnon Levi ${ }^{1}$, Patrick Wechter ${ }^{1}$, Laura Massey ${ }^{1}$, Louisa Carter ${ }^{2}$, Donald Hopkins ${ }^{3}$ \\ ${ }^{1}$ USDA, ARS, U.S. Vegetable Laboratory, Charleston, USA; ${ }^{2}$ Department of Genetics, University of Georgia, Athens, USA; \\ ${ }^{3}$ University of Florida, Mid-Florida Research and Education Center, Apopka, USA. \\ Email: amnon.levi@ars.usda.gov
}

Received October $1^{\text {st }}$, 2010; revised February $15^{\text {th }}, 2011$; accepted February $28^{\text {th }}, 2011$.

\begin{abstract}
There is limited genetic mapping data useful for breeding programs of watermelon. Introgression lines should be a useful tool for genetic studies and genetic enhancement of watermelon cultivars. In this study, we used an advanced recombinant population $\left(\mathrm{BC}_{2} \mathrm{~F}_{2}\right)$ to identify and map chromosomal segments of the wild watermelon Citrullus lanatus var. citroides that were incorporated in the genome of the watermelon cultivar Crimson Sweet (Citrullus lanatus var. lanatus). An advanced recombinant population $\left(B_{2} F_{2}\right)$ was constructed using a United States Plant Introduction (PI) 494817 (C. lanatus var. citroides) (known to have moderate resistance to bacterial fruit blotch) as a donor parent, and the elite watermelon cultivar Crimson Sweet (C. lanatus var. lanatus) as the recurrent parent. The genetic linkage map consists of 272 markers, including 89 sequence-related amplified polymorphism (SRAP), 72 targeted region amplification polymorphism (TRAP), and 111 high frequency oligonucleotide-targeting active gene (HFO-TAG) markers. The 272 markers were assembled into 51 linkage groups, covering a total genetic distance of $2162 \mathrm{cM}$, with an average genetic distance of $7.9 \mathrm{cM}$ between markers. Also, we expended the genetic linkage map for watermelon derived from a testcross population \{Griffin 14113 [C. lanatus var. citroide (L.H. Bailey) Mansf.] x watermelon cultivar New Hampshire Midget (C. lanatus var. lanatus)\} x PI 386015 [C. colocynthis (L.) Schrad.]. The genetic linkage map based on the test cross population consists of 558 markers that cover a genetic distance of $2760.8 \mathrm{cM}$. This linkage map consists of 41 linkage group, including 10 large linkage groups (ranging from102 - $240 \mathrm{cM}$ ), nine intermediate size linkage groups (ranging from 62 - $93 \mathrm{cM}$ ), and 22 small linkage groups (ranging from 2 - $56 \mathrm{cM}$ ). Comparative mapping between these two linkage maps identified high consensus in 25 HFO-TAG markers and one TRAP marker that represent 8 linkage groups in the $B_{2} F_{2}$ population and 9 linkage groups in the testcross population. These results indicate that HFO-TAG markers should be useful in comparative mapping. The extended genetic maps and the genetic population in this study should be useful in breeding programs using marker assisted selection and should serve as a platform for further development of introgression lines for watermelon.
\end{abstract}

Keywords: Testcross, Recombinant Population, SRAP, TRAP, HFO-TAG, DNA Markers, Genetic Diversity, Comparative Mapping

\section{Introduction}

Watermelon is an important vegetable crop worldwide. It belongs to the xerophytes genus Citrullus Schrad. ex Eckl. et Zeyh. Diverse populations of this genus grow freely in southern Africa which is considered to be its centre of origin. The genus Citrullus comprises four known diploid $(\mathrm{n}=11)$ species. Among them is the annual Citrullus lanatus (Thunb.) Matsum et Nakai. This species is indigenous to the arid sandy regions of southern Africa [1]. It is considered the progenitor of the red, sweet cultivated watermelon (C. lanatus var. lanatus) and the Tsamma watermelon (C. lanatus var. citroides) (also known as the citron or cow melon) $[2,3]$.

Previous studies [4] indicated that North American heirloom cultivars share a narrow genetic base, while a wide genetic distance exists between the heirlooms ( $C$. lanatus var. lanatus) and the related subspecies $C$. lanatus var. citroides, sharing less than $60 \%$ of their alleles [5]. A major objective of the watermelon industry is to develop breeding lines and cultivars with enhanced re- 
sistance to diseases and pests. A number of PIs of $C$. lanatus var. citroides have been shown to contain resistance to major diseases and pests of watermelon, including resistance to gummy stem blight [6], Fusarium wilt [7], and root-knot nematodes [8]. Also, many of the $C$. lanatus var. citroides PIs have more plant vigor and a larger crown size and plant density than watermelon cultivars. Although the C. lanatus var. citroides fruits have white or green flesh and thick rind, they should serve as a useful source for alleles that have been lost during many years of domestication of the red, sweet cultivated watermelon. It is easy to make crosses between watermelon cultivars (C. lanatus var. lanatus) and C. lanatus var. citroides PIs. However, introgression of favorable alleles from the wild watermelon into cultivars is difficult because many favorable alleles are closely linked to undesired fruit traits.

Because of this wide genetic distance[4,5,9], $\mathrm{F}_{2}$ genetic populations derived from crosses between watermelon cultivars (C. lanatus var. lanatus) and C. lanatus var. citroides PIs showed strong segregation distortion for most alleles [9-13]. Segregation distortion is common in wide crosses due to differences in chromosome structure (meiotic drive) [11], and may produce quasi (nonrepresentative) genetic linkage among molecular-based markers [12-14]. Thus, classical genetic models in $F_{2}$ populations derived from a cross between $C$. lanatus var. citroides PIs and cultivated watermelon (C. lanatus var. lanatus) may need further evaluation because of possible segregation distortion for most alleles.

The genetic linkage maps that we have constructed for watermelon are derived from a backcross [9] or a testcross population [12,13]. These maps have been useful in identifying and mapping disease or pest resistance genes [15-17]. However, because of the distorted segregation for a large number of alleles, they have limited use in conventional breeding programs and in identifying quantitative trait loci (QTLs).

We have recently begun a study to identify markers for resistance to bacterial fruit blotch, an important seedborne bacterial disease in watermelon. Bacterial fruit blotch, caused by the phytopathogenic bacterium Acidovorax avenae subsp. citrulli has been documented in many countries world-wide. This seed-borne pathogen can infect plants at any growth stage, but is typically seen at the seedling stage or at the mature fruit stage [18]. The first reported outbreak in the United States was in a commercial watermelon field in Florida in 1989 [18,19]. In addition to watermelon, this pathogen can cause severe disease on most cucurbits $[18,20]$. In recent years there have been several reports of new outbreaks of bacterial fruit blotch in the U.S., many of which are associated with watermelon [21].
Only limited chemical options exist for addressing this disease, none of which are very effective [20,21]. With such limitations in management of this disease, a source of genetic resistance (currently no cucurbit cultivar has resistance to this disease) in watermelon would be extremely beneficial to the industry. A screen of over 1,300 Citrullus spp. and Praecitrullus fistulosa accessions from the U.S. germplasm collection yielded 5 PIs with moderate levels of resistance to this disease. One of these PIs was a C. lanatus var. citroides PI 494817 [22]. To date, PI 494817 is the only known source of resistance to this disease. Studies indicate that this resistance might be a result of a complex mode of inheritance that involved several genes [23]. In order to better understand this resistance at the genetic level, we developed a $\mathrm{F}_{2}$ population of $C$. lanatus var. citroides PI $494817 \times$ C. lanatus var. lanatus watermelon cultivar Crimson Sweet for a mapping and marker study. The results of that study were inconclusive due to the wide genetic distance between PI 494817 and Crimson Sweet [4,5,9] and possibly due to distorted segregation in such wide crosses [13]. Further germplasm evaluation and genetic studies are needed to determine the mode of inheritance of resistance to bacterial fruit blotch in watermelon.

To overcome these limitations in genetic mapping we generated advanced recombinant populations $\left(\mathrm{BC}_{2} \mathrm{~F}_{2}\right.$ or $\mathrm{BC}_{3} \mathrm{~F}_{2}$ ) for mapping of genetic regions that are being incorporated from $C$. lanatus var. citroides PIs into watermelon cultivars. These populations should exhibit normal segregation ratios for a large number of markers, as was suggested in genetic improvement studies of barley [24]. These advanced recombinant populations can be useful for genetic mapping and the identification of chromosomal segments that were introgressed from the genome of a C. lanatus var. citroides PI into the genome of a watermelon cultivar.

Eshed and Zamir [25,26] showed that introgression line populations can be useful for genetic mapping of quantitative trait loci (QTLs) and for enhancing elite varieties with exotic alleles that were lost during domestication. They proposed to develop introgression lines (ILs) by repeated backcrossing, thus introgressing chromosomal segments from an exotic wild accession into the background of an elite variety (recurrent parent). The resulting introgression lines should facilitate the dissection of quantitative traits into Mendelian factors [27]. Sets of introgression lines have been developed for different crops, including tomato [28], lettuce [29], wheat [30], soybean [31], and Brassica oleracea [32]. However, there is no report on the development of introgression lines in watermelon.

Our long term objective is to expand the genetic diversity in cultivated watermelon by establishing a set of lines 
into which chromosomal segments containing useful disease resistance from $C$. lanatus var. citroides have been introgressed into the genome of watermelon cultivars $(C$. lanatus var. lanatus). These populations will be used in future studies of both phenotypic traits associated with the wild watermelons as well as with disease and pest resistance transferred from the wild watermelons into watermelon cultivars.

In this study, we examined 1) an advanced recombinant genetic population $\left(\mathrm{BC}_{2} \mathrm{~F}_{2}\right)$ for genetic mapping of watermelon, 2) if chromosomal segments of $C$. lanatus var. citroides PI 494817 (known to have moderate resistance to bacterial fruit blotch) $[20,22,23]$ that were incorporated into the genomic background of the watermelon cultivar Crimson Sweet (C. lanatus var. lanatus) could be mapped and be used for construction of introgression lines. Also, we expanded the genetic linkage map for watermelon derived from a testcross population \{plant accession Griffin 14113 [C. lanatus var. citroide (L. H. Bailey) Mansf.] x watermelon cultivar New Hampshire Midget (C. lanatus var. lanatus)\} x PI 386015 [C. colocynthis (L.) Schrad.] [12,13] and performed comparative mapping between the two maps using high frequency oligonucleotide-targeting active genes (HFO-TAG) markers [33] and targeted region amplified polymorphism (TRAP) markers [34].

\section{Materials and Methods}

Watermelon cv. Crimson Sweet and plant introduction PI 494817 were used to create a $\mathrm{BC}_{2} \mathrm{~F}_{2}$ population at the Mid-Florida Research and Education Center, Apopka, FL. Hopkins and Thompson [22] determined that PI 494817 (C. lanatus var. citroides) contains resistance to bacterial fruit blotch (BFB). The most resistant PI 494817 plant was self-pollinated and the progeny were re-evaluated for resistance to BFB in two successive generations. An $F_{3}$ plant containing resistance to $\mathrm{BFB}$ was selected and was crossed with 'Crimson Sweet', from which an $\mathrm{F}_{2}$ population was produced, progeny were evaluated and the most resistant plant was backcrossed to the cultivar. $A B_{1} F_{2}$ population was produced by self-pollination of one plant and was evaluated for BFB resistance. The most resistant plant was selected and backcrossed with 'Crimson Sweet'. A similar scheme was applied in subsequent generations to produce $\mathrm{BC}_{2} \mathrm{~F}_{2}$ and $\mathrm{BC}_{3} \mathrm{~F}_{2}$ populations (as shown in Figure 1).

Plant material: Young leaves (10 g) were collected from each $\mathrm{BC}_{2} \mathrm{~F}_{2}$ plant, and stored at $-80^{\circ} \mathrm{C}$.

Isolation of DNA: To avoid co-isolation of polysaccharides, polyphenols, and other secondary compounds that damage DNA, we used an improved procedure for isolation of DNA from young leaves of watermelon [35]. SRAP and TRAP analysis: Ninety-eight SRAP primer

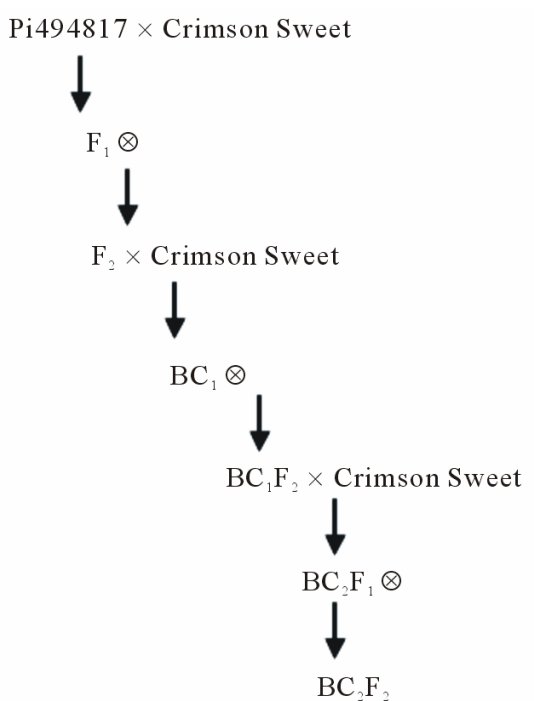

Figure 1. Breeding scheme for producing the $\mathrm{BC}_{2} \mathrm{~F}_{2}$ population used for genetic mapping in this study.

combinations (Table 1) were tested with the donor parent PI 494817, the recurrent parent 'Crimson Sweet' and the $94 \mathrm{BC}_{2} \mathrm{~F}_{2}$ progeny. Fragment analysis was performed on capillary system CEQ8800 DNA Genetic Fragment Analysis System (Beckman Coulter, Fullerton, CA). The forward primers were labeled with one of 3 WellRED dyes (D2, D3, or D4) (Proligo, Boulder, CO). To confirm correct dye balance, the amount of dye-labeled primer added to the PCR cocktail was optimized for each primer. Each $10 \mu \mathrm{L}$ reaction contained 1X PCR buffer (Promega, Madison, Wis.), $2.5 \mathrm{mM} \mathrm{MgCl}$, $200 \mu \mathrm{M}$ dNTPs (Sigma, St. Louis, MO), $30 \mathrm{ng}$ of reverse primer (IDT, Coraville, IA), 0.25 U Taq DNA polymerase (Promega, Madison, Wis.) and 25 ng of DNA. In addition, WellRED dyeabeled forward primers were added in the following amounts: $0.1 \mu \mathrm{M}$ for a D4 primer; $0.2 \mu \mathrm{M}$ for a D3 primer; or $0.2 \mu \mathrm{M}$ for a D2 primer. Samples were subjected to the following thermal profile for amplification in a PCR thermocycler (PTC 200, MJ Research): 5 min of DNA denaturizing at $94^{\circ} \mathrm{C}$, five cycles of three steps: $1 \mathrm{~min}$ of denaturing at $94^{\circ} \mathrm{C}, 1 \mathrm{~min}$ of annealing at $35^{\circ} \mathrm{C}$ and 2 min of elongation at $72^{\circ} \mathrm{C}$. In the following $30 \mathrm{cy}-$ cles the annealing temperature was increased to $50^{\circ} \mathrm{C}$, with a final elongation step of $5 \mathrm{~min}$ at $72^{\circ} \mathrm{C}[13,33]$. The PCR products were analyzed using the CEQ8800 (Beckman Coulter, Fullerton, CA ) by pooling $0.35 \mu \mathrm{L}$ of the D4 reaction, $0.45 \mu \mathrm{L}$ of the D3 reaction, $0.55 \mu \mathrm{L}$ of the D2 reaction, $0.28 \mu \mathrm{L}$ of $\mathrm{D} 1$ size standard, and $30 \mu \mathrm{L}$ of de-ionized formamide in a 96 well PCR plate. Samples were run on the CEQ8800 using the fragment 3 parameters and analyzed using the built-in fragment analysis software provided with the system. Fragments that ranged in size of 75 - 400 bp could be scored with high 
confidence.

HFO-TAG Analysis: Thirty-six HFO-TAG primers (Ta- ble 2) were used in this study were previously described [33].

Table 1. Sequence related amplified polymorphism (SRAP) forward (FP) and reverse primers (RP) used in this study.

\begin{tabular}{|c|c|c|c|}
\hline FLP & Primer sequence 5' to 3' & RUP & Primer sequence 5' to 3' \\
\hline Me1 & TGAGTCCAAACCGGATA & ba1 & GTCGAGCTGCCAATTATA \\
\hline Me2 & TGAGTCCAAACCGGAGC & ba2 & GTCGAGCTGCCAATTAAT \\
\hline Me3 & TGAGTCCAAACCGGAAT & ba3 & GTCGAGCTGCCAATTTGC \\
\hline Me4 & TGAGTCCAAACCGGACC & ba4 & GTCGAGCTGCCAATTTTT \\
\hline Me5 & TGAGTCCAAACCGGAAG & ba5 & GTCGAGCTGCCAATTAAA \\
\hline Ab1 & AGTGATTCAACCGGAGA & ba6 & GTCGAGCTGCCAATTAAC \\
\hline Ab2 & AGTGATTCAACCGGATA & ba7 & GTCGAGCTGCCAATTAAG \\
\hline Ab3 & AGTGATTCAACCGGAGC & ba8 & GTCGAGCTGCCAATTATT \\
\hline Wm1 & ATTTTAGCAGCCGGGTA & ba9 & GTCGAGCTGCCAATTATC \\
\hline Wm2 & ATTTTAGCAGCCGGAGC & ba10 & GTCGAGCTGCCAATTATG \\
\hline Wm3 & ATTTTAGCAGCCGGGTT & ba11 & GTCGAGCTGCCAATTTGA \\
\hline Wm4 & ATTTTAGCAGCCGGGCA & ba12 & GTCGAGCTGCCAATTTGT \\
\hline Wm5 & ATTTTAGCAGCCGGGCA & em1 & GACTGCGTACGAATTAAT \\
\hline $\mathrm{Cl} 1$ & ATAGATACGCCCGGATA & em2 & GACTGCGTACGAATTTGC \\
\hline $\mathrm{Cl} 2$ & ATAGATACGCCCGGAGC & em3 & GACTGCGTACGAATTGAC \\
\hline $\mathrm{Cl} 3$ & ATAGATACGCCCGGACA & em4 & GACTGCGTACGAATTTGA \\
\hline $\mathrm{Cl} 4$ & ATAGATACGCCCGGATG & em5 & GACTGCGTACGAATTAAC \\
\hline \multirow[t]{27}{*}{$\mathrm{Cl} 5$} & ATAGATACGCCCGGAGT & em6 & GACTGCGTACGAATTGCA \\
\hline & & mw1 & GGAGGTCGAAAATTGTA \\
\hline & & mw2 & GGAGGTCGAAAATTGTC \\
\hline & & mw3 & GGAGGTCGAAAATTGTT \\
\hline & & mw4 & GGAGGTCGAAAATTGAG \\
\hline & & mw5 & GGAGGTCGAAAATTGCT \\
\hline & & lc1 & CCATCTAGGCAATTCGA \\
\hline & & lc2 & CCATCTAGGCAATTGGT \\
\hline & & lc3 & CCATCTAGGCAATTTGG \\
\hline & & lc4 & CCATCTAGGCAATTAGG \\
\hline & & lc5 & CCATCTAGGCAATTTGC \\
\hline & & nw1 & ACAATGGCGGAATTGGT \\
\hline & & nw2 & ACAATGGCGGAATTCGA \\
\hline & & nw3 & ACAATGGCGGAATTTGG \\
\hline & & nw4 & ACAATGGCGGAATTAGG \\
\hline & & nw5 & ACAATGGCGGAATTTGC \\
\hline & & aw1 & TGAAAGAGGGAATTGGC \\
\hline & & aw2 & TGAAAGAGGGAATTGGG \\
\hline & & aw3 & TGAAAGAGGGAATTCGA \\
\hline & & aw4 & TGAAAGAGGGAATTGGT \\
\hline & & aw5 & TGAAAGAGGGAATTCGG \\
\hline & & se1 & GAGAGAGAGAAATTGGC \\
\hline & & se2 & GAGAGAGAGAAATTCCG \\
\hline & & se3 & GAGAGAGAGAAATTGCG \\
\hline & & re1 & СТСТСТСТСТAATTGGG \\
\hline & & re2 & СТСТСТСТСТАATTGGC \\
\hline & & re3 & СТСТСТСТСТАATTGСС \\
\hline
\end{tabular}


Table 2. The 36 HFO-TAG (high frequency oligonucleotides-targeting active genes) primers used in this study. The number of nucleotide bases for each primer $(B)$, the GC content $(0.875=87.5 \%$ and $1=100 \%)$ for each primer, the melting temperature (Tm) $\left({ }^{\circ} \mathrm{C}\right)$, and the annealing temperature (Ta) $\left({ }^{\circ} \mathrm{C}\right)$ used in PCR. In addition, the total number of fragments (TF) that were produced by each of the HFO-TAG primers and the number of fragments (MF) that could be mapped with $\mathrm{BC}_{2} \mathrm{~F}_{2}$ population.

\begin{tabular}{|c|c|c|c|c|c|c|c|}
\hline \multirow{2}{*}{ Primer } & \multirow{2}{*}{ Oligos } & \multirow{2}{*}{ B (no.) } & \multirow{2}{*}{ GC Content } & Tm & Ta & TF & MF \\
\hline & & & & $\left({ }^{\circ} \mathrm{C}\right)$ & $\left({ }^{\circ} \mathrm{C}\right)$ & (no.) & (no.) \\
\hline HFO-14 & GCGGCGGA & 8 & 0.875 & 38.4 & 45 & 6 & 4 \\
\hline HFO-20 & GGCGGCGA & 8 & 0.875 & 38.4 & 45 & 9 & 9 \\
\hline HFO-23 & ACGGCGGC & 8 & 0.875 & 39.1 & 45 & 16 & 12 \\
\hline HFO-31 & CGCCGCCA & 8 & 0.875 & 39.1 & 45 & 5 & 3 \\
\hline HFO-37 & CGGCGCCG & 8 & 1 & 40.9 & 45 & 1 & 1 \\
\hline HFO-44 & CGCCGGCG & 8 & 1 & 40.9 & 45 & 5 & 5 \\
\hline HFO-49 & GCGGCGGT & 8 & 0.875 & 39.1 & 45 & 7 & 2 \\
\hline HFO-50 & ACCGCCGC & 8 & 0.875 & 39.1 & 45 & 2 & 1 \\
\hline HFO-55 & CCGCCGCT & 8 & 0.875 & 38.3 & 45 & 2 & 2 \\
\hline HFO-56 & AGCGGCGG & 8 & 0.875 & 38.3 & 45 & 8 & 7 \\
\hline HFO-60 & TCGGCGGC & 8 & 0.875 & 38.4 & 45 & 10 & 7 \\
\hline HFO-61 & GCCGCCGA & 8 & 0.875 & 38.4 & 45 & 1 & 1 \\
\hline HFO-66 & CCGCCGGA & 8 & 0.875 & 36.7 & 45 & 4 & 1 \\
\hline HFO-67 & GCCGCTGC & 8 & 0.875 & 36.8 & 45 & 9 & 4 \\
\hline HFO-68 & GCAGCGGC & 8 & 0.875 & 36.8 & 45 & 3 & 0 \\
\hline HFO-71 & CCACCGCCG & 9 & 0.889 & 42.4 & 45 & 5 & 3 \\
\hline HFO-72 & CGGCGGTGG & 9 & 0.889 & 42.4 & 45 & 2 & 1 \\
\hline HFO-75 & CCGCCGGC & 8 & 1 & 41.9 & 45 & 2 & 0 \\
\hline HFO-76 & GCCGGCGG & 8 & 1 & 41.9 & 45 & 1 & 1 \\
\hline HFO-77 & CCTCCGCCG & 9 & 0.889 & 41.2 & 45 & 3 & 1 \\
\hline HFO-78 & CGGCGGAGG & 9 & 0.889 & 41.2 & 45 & 5 & 3 \\
\hline HFO-100 & CGGCGGCT & 8 & 0.875 & 38.3 & 45 & 1 & 0 \\
\hline HFO-105 & AGCCGCCG & 8 & 0.875 & 38.3 & 45 & 10 & 3 \\
\hline HFO-117 & TGCGGCGG & 8 & 0.875 & 39.1 & 45 & 4 & 2 \\
\hline HFO-116 & CCGCCGCA & 8 & 0.875 & 39.1 & 45 & 2 & 2 \\
\hline HFO-120 & AGGCGGCG & 8 & 0.875 & 38.3 & 45 & 10 & 9 \\
\hline HFO-132 & GGCCGCCG & 8 & 1 & 41.9 & 45 & 4 & 2 \\
\hline HFO-152 & TCCACCGCC & 9 & 0.778 & 38.2 & 45 & 6 & 3 \\
\hline HFO-153 & GGCGGTGGA & 9 & 0.778 & 38.2 & 45 & 3 & 2 \\
\hline HFO-154 & TGCCGCCG & 8 & 0.875 & 39.1 & 45 & 9 & 3 \\
\hline HFO-158 & CGGCGGCA & 8 & 0.875 & 39.1 & 45 & 4 & 3 \\
\hline HFO-175 & CCACCGCCA & 9 & 0.778 & 38.9 & 45 & 3 & 2 \\
\hline HFO-179 & ACGCCGCC & 8 & 0.875 & 39.1 & 45 & 6 & 1 \\
\hline HFO-182 & GGCGGCGT & 8 & 0.875 & 39.1 & 45 & 13 & 7 \\
\hline HFO-184 & CGGCAGCG & 8 & 0.875 & 36.3 & 45 & 5 & 2 \\
\hline HFO-187 & GGGCGGCG & 8 & 1 & 41.9 & 45 & 9 & 8 \\
\hline
\end{tabular}


Marker nomenclature: The SRAP markers were designated by combining the forward (first) and reverse primers (second) with the marker size (third) (Table 1). For example: the SRAP marker Wm41c5-183c (on linkage group 1) was produced by the forward primer $\mathrm{Wm} 4$ and by the reverse primer 1c5 (Table 1) and has a $183 \mathrm{bp}$ size. It is unique to the recurrent parent "Crimson Sweet" and therefore was designated as "c" on the right end. The TRAP markers were designated by combining the forward (first) and reverse primers (second) with the marker size (third) (Table 3). For example the TRAP marker Me3-1C05-1-116 (on linkage group2) was produced by the forward primer Me3 and the reverse primer 1C05-1, and had the size of 122 bp and unique to the donor parent PI 494817. The HFO-TAG markers were designated as HFO and the size of marker they produced (Table 2).

Marker scoring: Markers that were unique to one of the parents, PI 494817 or "Crimson Sweet", and were present in the $\mathrm{BC}_{2}$ parent, and were segregating in a ratio of $1: 1$ could be scored for mapping in the $\mathrm{BC}_{2} \mathrm{~F}_{2}$ population (Table 4, Figure 2). The SRAP and HFO-TAG markers were scored using the built-in fragment analysis software (provided with the Beckman CEQ8800 system).

Linkage analysis of markers in the $B C_{2} F_{2}$ population: Linkage analysis was performed with the JoinMap 3.0 software (Kyazma B.V., Netherlands) [36] using default options. All markers were analyzed for linkage, and recombination fractions were converted into map distances (centimorgans, cM) with the Kosambi function. High threshold LOD scores of 7.0 - 10.0 were used for final mapping of linkage groups following removal of loci showing weak or suspect linkages. Segregation ratio distortion was evaluated with a $\boldsymbol{X}^{2}$ test for goodness of fit based on the segregation expectations of 1:1 for markers in an $F_{2}$ population [36].

Linkage analysis of markers in a testcross population: As with the $\mathrm{BC}_{2} \mathrm{~F}_{2}$ population, linkage analysis was performed with the JoinMap 3.0 software (Kyazma B.V., Netherlands0 [36] with default options. All markers were analyzed for linkage, and recombination fractions were converted into map distances (centimorgans, cM) with the Kosambi function. High threshold LOD scores of 7.0 - 10.0 were used for final mapping of linkage groups following removal of loci showing weak or suspect linkages. Segregation ratio distortion was evaluated with a $\boldsymbol{X}^{2}$ test for goodness of fit based on the segregation expectations of 1:1 for markers in an $F_{2}$ population [36]. Here we used the linkage mapping data that already exist for 360 markers [13] and experimented with additional markers, including HFO-TAG [26] and (TRAP) markers [34] using the testcross progeny to expend the existing genetic map [13].

Comparative mapping between the testcross and the $B C_{2} F_{2}$ genetic linkage maps:

A comparative genetic mapping was conducted using the JoinMap 3.0 software with the regression mapping

Table 3. The target region amplification polymorphism (TRAP) primer pairs. Each primer pair is a combination of an SRAP (forward) and a watermelon EST (reverse) primer, MP is the number of TRAP markers that could be mapped on the linkage map.

\begin{tabular}{cccc}
\hline SRAP-EST & SRAP Forward Primer & EST Reveres Primer \\
\hline Primer Combination & & \\
Me1-1C05-1 & 5' TGAGTCCAAACCGGATA & 5' GCAAAGGAATAAATCTTCCTCCA \\
Me1-1E05-1 & 5' TGAGTCCAAACCGGATA & 5' AGCAACACCAAACGCACAGA \\
Me1-1D08-1 & 5' TGAGTCCAAACCGGATA & 5' TTCCTTCCAATTTCATCATTCA \\
Me5-1D08-1 & 5' TGAGTCCAAACCGGAAG & 5' TTCCTTCCAATTTCATCATTCA \\
Me5-1C05-1 & 5' TGAGTCCAAACCGGAAG & 5' GCAAAGGAATAAATCTTCCTCCA \\
Me3-1C05-1 & 5' TGAGTCCAAACCGGAAT & 5' GCAAAGGAATAAATCTTCCTCCA \\
Me3-1D08-1 & 5' TGAGTCCAAACCGGAAT & 5' TTCCTTCCAATTTCATCATTCA \\
Me1-2A12-1 & 5' TGAGTCCAAACCGGATA & 5' GAAACAAACCTAAGGTGCAAAAA \\
Me1-1H11-1 & 5' TGAGTCCAAACCGGATA & 5' TGGGTAATCCACCTGGCAAA \\
Me5-1H11-1 & 5' TGAGTCCAAACCGGAAG & 5' TGGGTAATCCACCTGGCAAA \\
Me3-1H11-1 & 5' TGAGTCCAAACCGGAAT & 5' TGGGTAATCCACCTGGCAAA \\
Wm2-1-A10-2 & 5' ATTTTAGCAGCCGGAGC & 5' GAGTTTCTCTCTTTCTTGATGTTCG \\
Wm3-1-A10-2 & 5' ATTTTAGCAGCCGGGTT & 5' GAGTTTCTCTCTTTCTTGATGTTCG & 5' \\
Me5-1E05-1 & 5' AGAGTCCAAACCGGAAG & 4 & 3 \\
\hline
\end{tabular}


Table 4. The linkage groups that were mapped using the $\mathrm{BC}_{2} \mathrm{~F}_{2}$ population. The linkage groups include high frequency oligoniclotide-targeting active gene (HFO-TAG) markers, sequence related amplified polymorphism (SRAP) markers, and targeted region amplification polymorphism (TRAP) markers. The total number of markers (TM) in each linkage group ranging from 2 to 40, and the genetic distance covered by each linkage group is ranging from 0 to $169 \mathrm{cM}$.

\begin{tabular}{|c|c|c|c|c|c|c|c|c|c|c|c|}
\hline Group & HFO & SRAP & TRAP & TM & LG Distance & Group & HFO & SRAP & TRAP & TM & LG Distance \\
\hline 1 & 30 & 4 & 6 & 40 & $169 \mathrm{cM}$ & 27 & 0 & 2 & 0 & 2 & $25 \mathrm{cM}$ \\
\hline 2 & 17 & 3 & 1 & 21 & $84 \mathrm{cM}$ & 28 & 0 & 2 & 0 & 2 & $26 \mathrm{cM}$ \\
\hline 3 & 6 & 2 & 0 & 8 & $107 \mathrm{cM}$ & 29 & 2 & 1 & 0 & 3 & $26 \mathrm{cM}$ \\
\hline 4 & 6 & 0 & 0 & 6 & $38 \mathrm{cM}$ & 30 & 0 & 0 & 3 & 3 & $47 \mathrm{cM}$ \\
\hline 5 & 4 & 0 & 0 & 4 & $17 \mathrm{cM}$ & 31 & 0 & 2 & 0 & 2 & $9 \mathrm{cM}$ \\
\hline 6 & 0 & 5 & 10 & 15 & $69 \mathrm{cM}$ & 32 & 3 & 0 & 0 & 3 & $13 \mathrm{cM}$ \\
\hline 7 & 1 & 3 & 1 & 5 & $55 \mathrm{cM}$ & 33 & 0 & 3 & 0 & 3 & $56 \mathrm{cM}$ \\
\hline 8 & 0 & 3 & 0 & 3 & $38 \mathrm{cM}$ & 34 & 0 & 3 & 0 & 3 & $56 \mathrm{cM}$ \\
\hline 9 & 0 & 3 & 0 & 3 & $46 \mathrm{cM}$ & 35 & 0 & 1 & 2 & 3 & $36 \mathrm{cM}$ \\
\hline 10 & 0 & 0 & 10 & 10 & $124 \mathrm{cM}$ & 36 & 3 & 0 & 0 & 3 & $5 \mathrm{cM}$ \\
\hline 11 & 0 & 0 & 5 & 5 & $40 \mathrm{cM}$ & 37 & 0 & 0 & 2 & 2 & $23 \mathrm{cM}$ \\
\hline 12 & 1 & 1 & 3 & 5 & $59 \mathrm{cM}$ & 38 & 0 & 0 & 2 & 2 & $11 \mathrm{cM}$ \\
\hline 13 & 4 & 10 & 1 & 15 & $113 \mathrm{cM}$ & 39 & 2 & 0 & 0 & 2 & $22 \mathrm{cM}$ \\
\hline 14 & 2 & 6 & 5 & 13 & $73 \mathrm{cM}$ & 40 & 2 & 0 & 0 & 2 & $8 \mathrm{cM}$ \\
\hline 15 & 5 & 5 & 3 & 13 & $61 \mathrm{cM}$ & 41 & 0 & 2 & 0 & 2 & $20 \mathrm{cM}$ \\
\hline 16 & 3 & 4 & 1 & 8 & $80 \mathrm{cM}$ & 42 & 0 & 2 & 0 & 2 & $10 \mathrm{cM}$ \\
\hline 17 & 5 & 0 & 0 & 5 & $16 \mathrm{cM}$ & 43 & 1 & 0 & 1 & 2 & $16 \mathrm{cM}$ \\
\hline 18 & 0 & 2 & 2 & 4 & $42 \mathrm{cM}$ & 44 & 0 & 1 & 1 & 2 & $20 \mathrm{cM}$ \\
\hline 19 & 0 & 3 & 1 & 4 & $54 \mathrm{cM}$ & 45 & 0 & 2 & 0 & 2 & $31 \mathrm{cM}$ \\
\hline 20 & 0 & 3 & 4 & 7 & $73 \mathrm{cM}$ & 46 & 0 & 1 & 1 & 2 & $23 \mathrm{cM}$ \\
\hline 21 & 6 & 0 & 0 & 6 & $96 \mathrm{cM}$ & 47 & 0 & 2 & 0 & 2 & $31 \mathrm{cM}$ \\
\hline 22 & 0 & 4 & 2 & 6 & $51 \mathrm{cM}$ & 48 & 1 & 0 & 1 & 2 & $21 \mathrm{cM}$ \\
\hline 23 & 2 & 0 & 0 & 2 & $8 \mathrm{cM}$ & 49 & 0 & 0 & 2 & 2 & $25 \mathrm{cM}$ \\
\hline 24 & 1 & 1 & 0 & 2 & $27 \mathrm{cM}$ & 50 & 2 & 0 & 0 & 2 & $0 \mathrm{cM}$ \\
\hline 25 & 0 & 3 & 0 & 3 & $36 \mathrm{cM}$ & 51 & 2 & 0 & 0 & 2 & $0 \mathrm{cM}$ \\
\hline \multirow[t]{2}{*}{26} & 0 & 0 & 2 & 2 & $26 \mathrm{cM}$ & & & & & & \\
\hline & & & & & & Total & 111 & 89 & 72 & 272 & $2,162 \mathrm{cM}$ \\
\hline
\end{tabular}

algorithm and a stringent log of the odds (LOD) score threshold of 7 - 10.

\section{Results and Discussion}

Polymorphism and mapping efficiency of markers using the $B_{2} F_{2}$ mapping population: The SRAP, TRAP, and HFO-TAG primers produced high number of polymorphic markers that complemented each other in the assembly of linkage groups. The 73 SRAP primer combinations (Table 1) produced 198 polymorphic markers (2.7 markers per primer), the 14 TRAP primer combina- tions (Table 2) produced 104 polymorphic markers (8 markers per primer), while the 36 HFO-TAG primers (Table 3) produced 195 polymorphic markers (5.4 markers per primer). Of the 497 polymorphic markers generated, one-hundred and twenty-three markers (24.7\%) had distorted segregation deviating from the expected 3:1 ratio, and were not included in the mapping analysis. This number of markers with distorted segregation is still relatively high, but considerably lower than from the number of such markers found in our mapping study using an $\mathrm{F}_{2}$ population [PI 296341(C. lanatus var. citroides) 
1

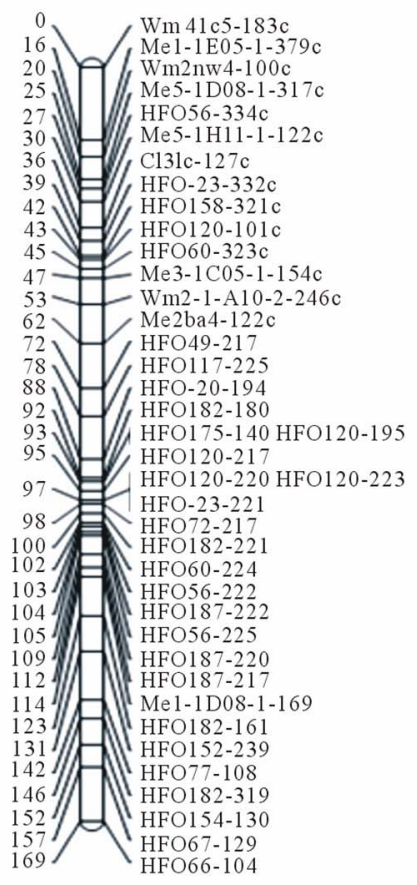

2

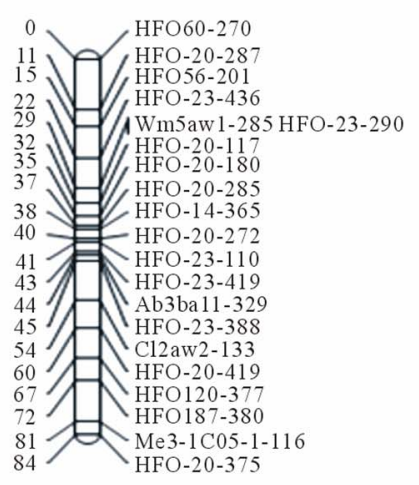

3

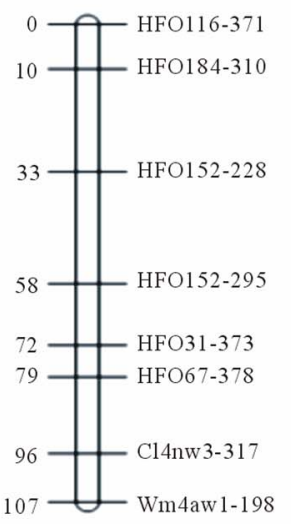

4

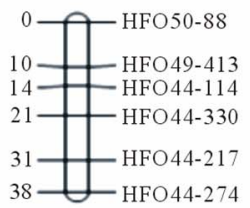

5

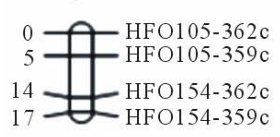

6

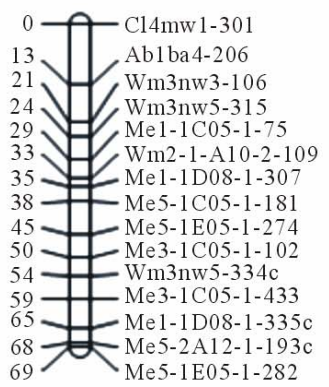

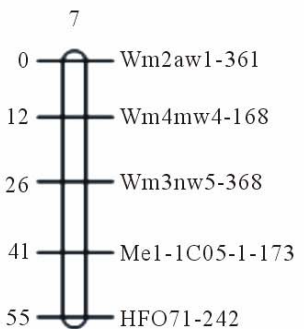

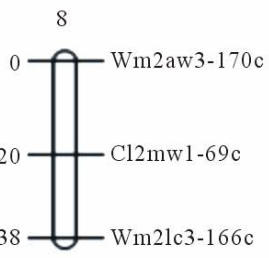

9

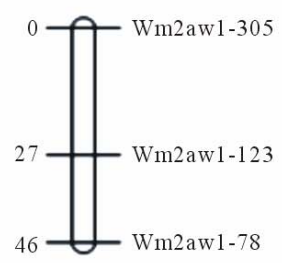

10

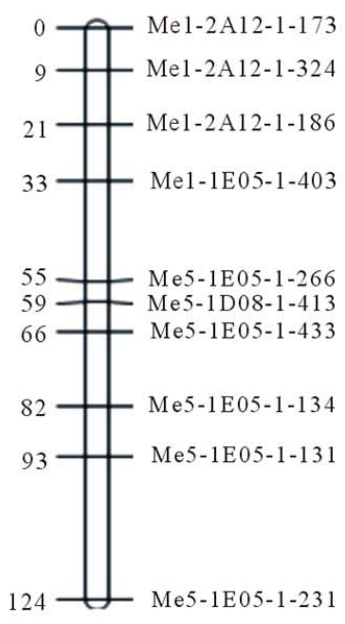

11

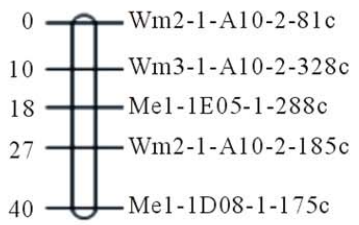

12

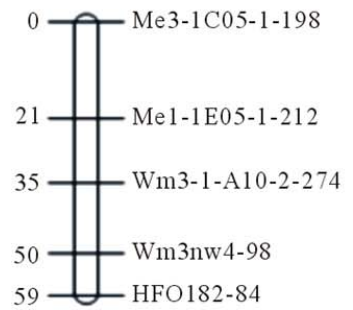

13

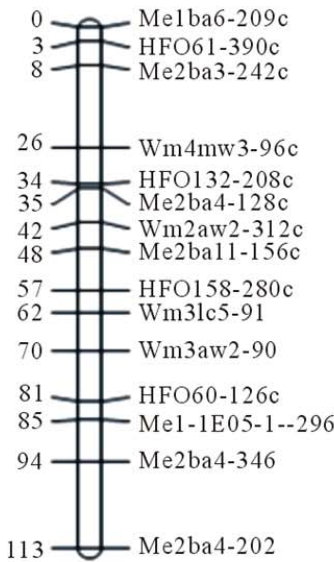



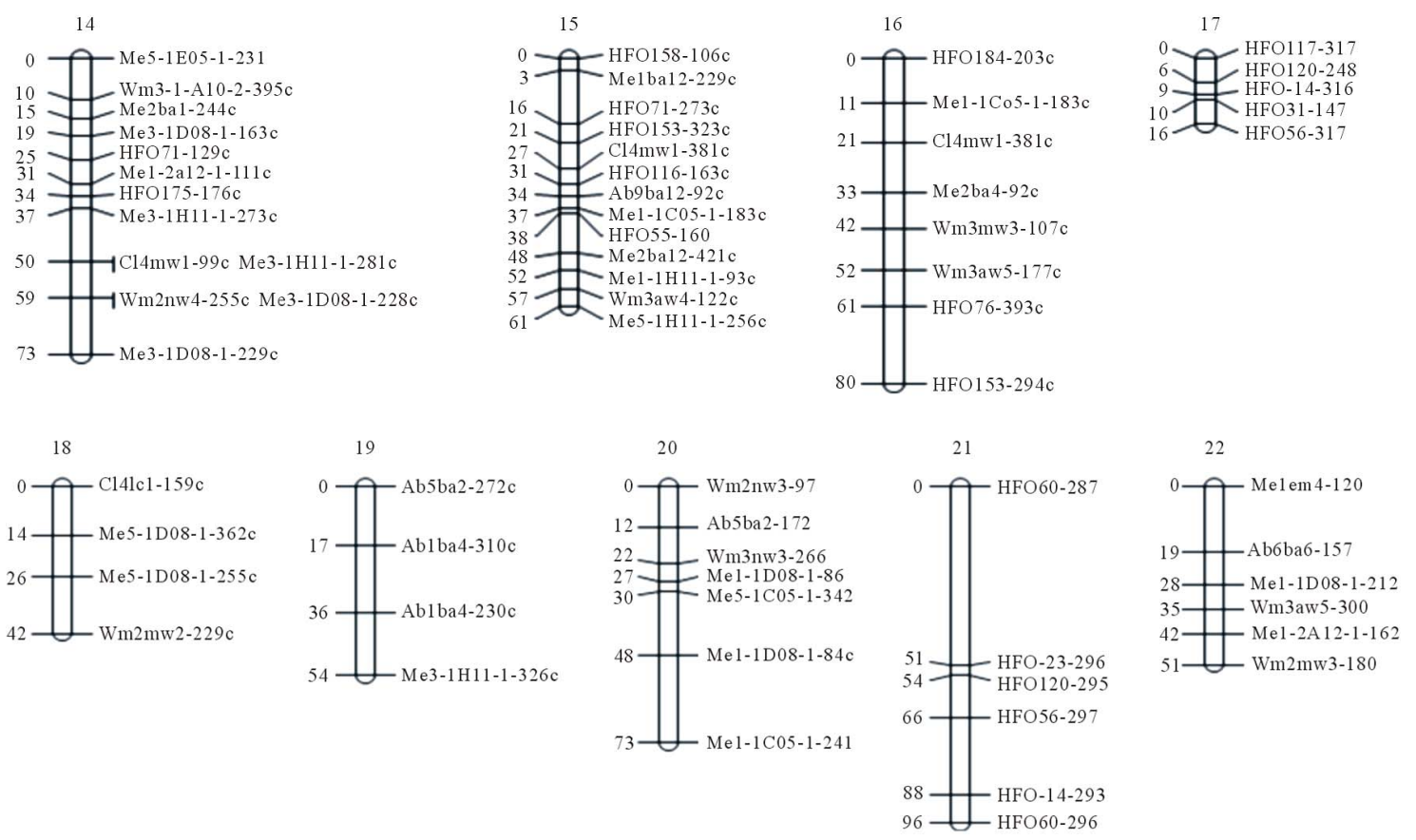

17

0 HFO117-317 6. $\mathrm{HFO} 20-248$ HFO56-317 THFO31-147

- 96 HFO60-296
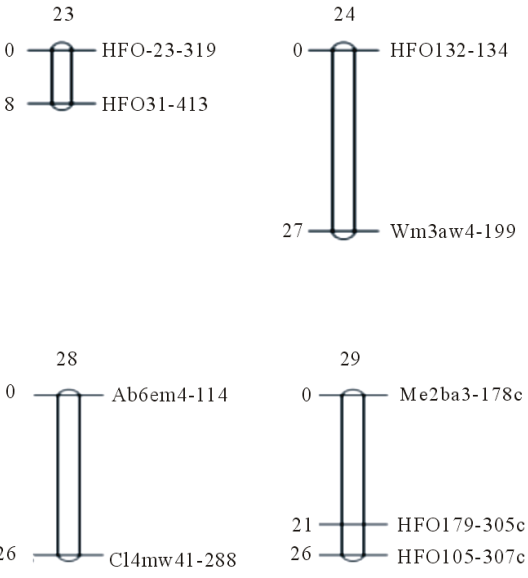
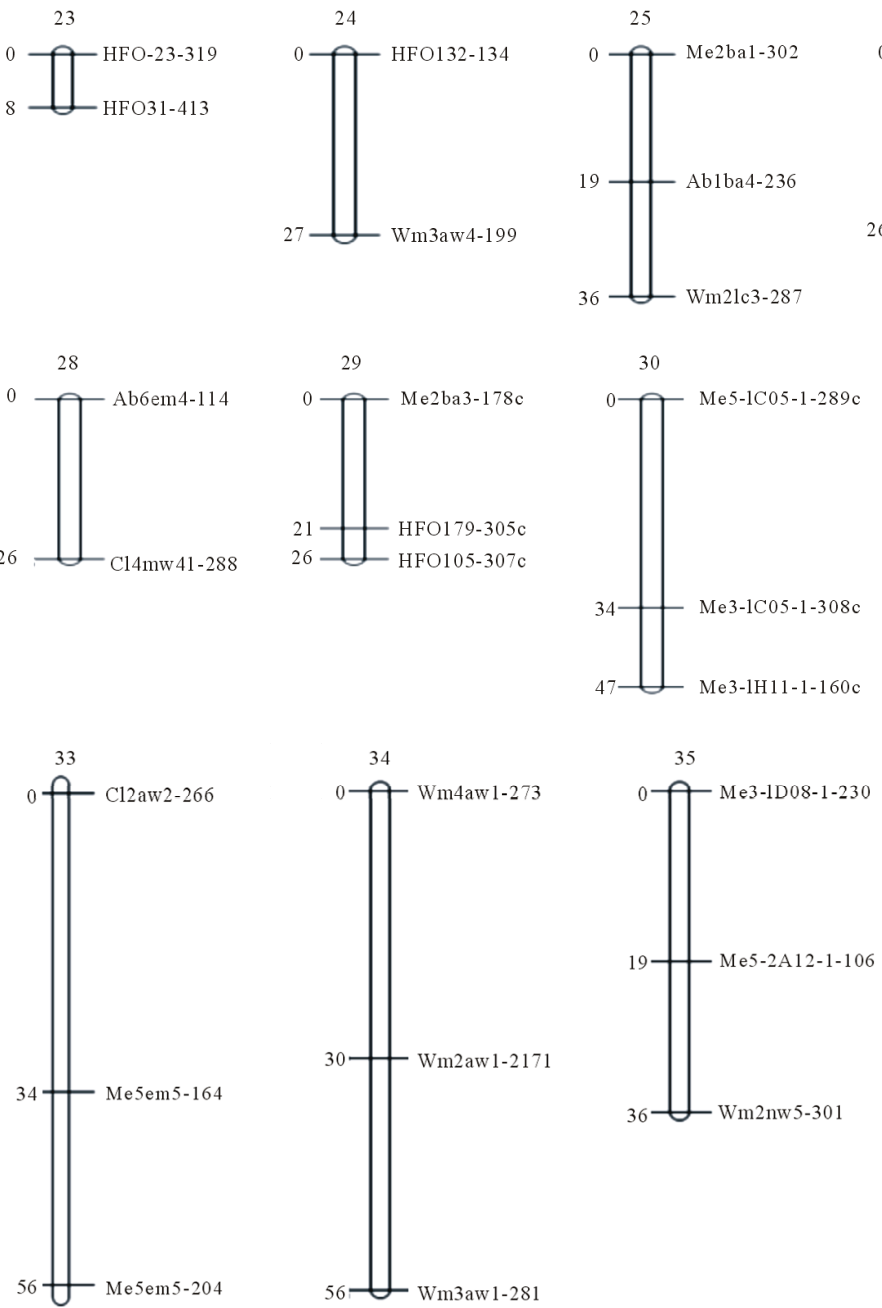

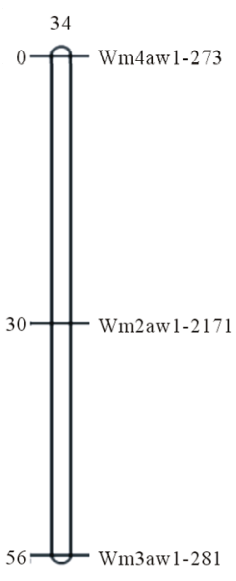

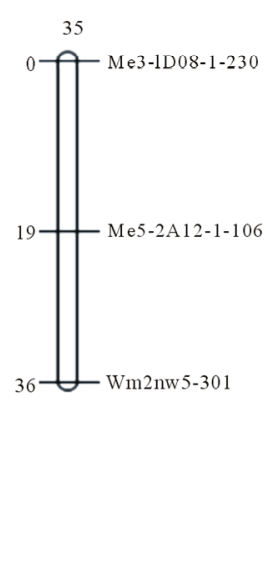

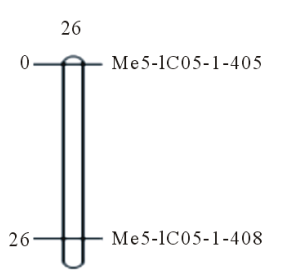

$\overbrace{9}^{31}$ Cl3mw4-159

32

$\left.\begin{array}{l}0 \\ 5-13\end{array}\right] \begin{aligned} & \text { HFO } 187-377 \mathrm{c} \\ & \text { HFO } 120-374 \mathrm{c} \\ & \text { HFO } 182-324 \mathrm{c}\end{aligned}$

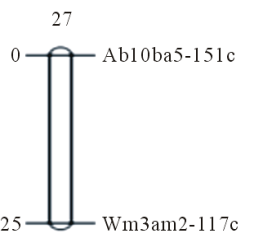

36

4 $\begin{array}{r}\text { HFO55-77c } \\ \text { HFO67-74c }\end{array}$

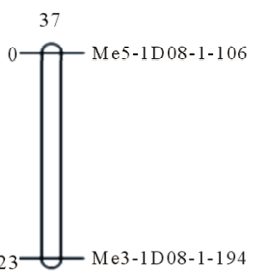



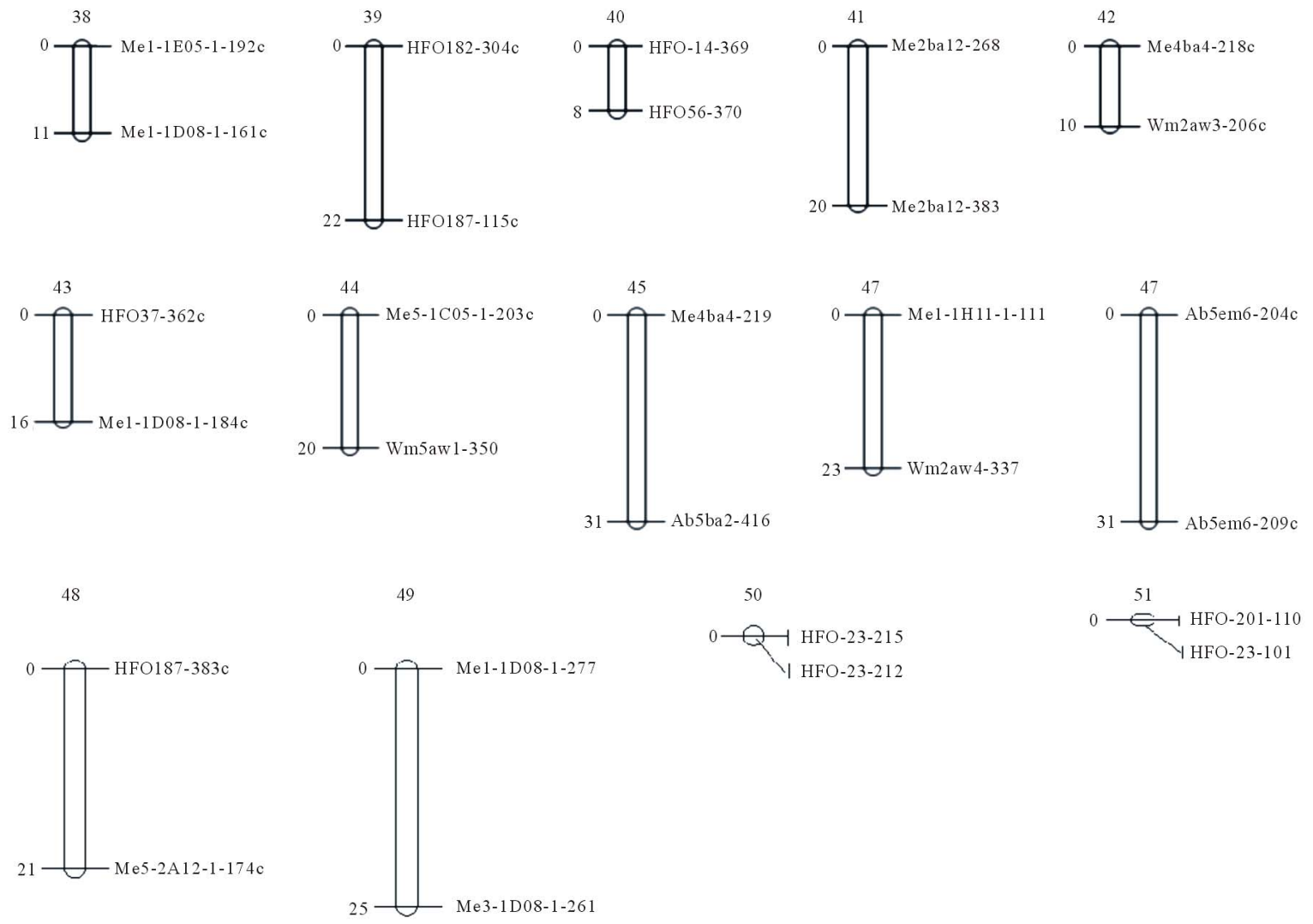

Figure 2. A genetic linkage map for watermelon derived from the $\mathrm{BC}_{2} \mathrm{~F}_{2}$ population [United States Plant Introduction (PI) 494817 (donor parent), and the watermelon cultivar Crimson Sweet (recurrent parent)] with 51 linkage groups, covering a total genetic distance of $2162 \mathrm{cM}$.

x New Hampshire Midget (Citrullus lanatus var. lanatus)]. In that study, most (over 90\%) of the RAPD or AFLP markers were skewed from the expected 3:1 ratio (Levi; unpublished data). In addition, the number of the skewed markers in the present study is less than that seen in the testcross mapping population \{plant accession Griffin 14113 [C. lanatus var. citroides (L.H. Bailey) Mansf.] x the watermelon cultivar New Hampshire Midget (C. lanatus var. lanatus)\} x PI 386015 [C. colocynthis (L.) Schrad.]\}, where $67.7 \%$ of the AFLP and $53.8 \%$ of SRAP markers were skewed from the expected 1:1 ratio [13]. It is possible that following two backcrosses and selection for a genotype showing no infection of bacterial fruit blotch in the $\mathrm{F}_{2}$ and in $\mathrm{BC}_{1} \mathrm{~F}_{2}$ populations, some of the chromosomal regions that cause segregation distortion were excluded, resulting in a normal (Mendelian) segregation ratio for a larger number of alleles in the $\mathrm{BC}_{2} \mathrm{~F}_{2}$ population. Xing et al. [37] showed that a quantitative trait locus ( $q S S P 7$ ) exhibiting distorted segregation in an $F_{2}$ population, had a normal segregation ratio in a $\mathrm{BC}_{2} \mathrm{~F}_{2}$ population, useful for genetic mapping of rice.

Of the remaining 389 polymorphic markers that were included in the mapping analysis, 272 (70.4\%) could be mapped with high confidence (Figure 2). The map consists of 89 SRAP, 111 HFO-TAG (Table 2) and 72 TRAP markers (Table 3) that were assembled into 51 linkage groups that cover a total genetic distance of 2,162 $\mathrm{cM}$, with an average genetic distance of $7.9 \mathrm{cM}$ between markers. (Table 4, Figure 2). However, in contrast with our previous studies using a $\mathrm{BC}_{1}$ or testcross populations which produced large linkage groups (133.5 - $264.5 \mathrm{cM}$ ) $[9,12,13]$, most linkage groups derived from the $\mathrm{BC}_{2} \mathrm{~F}_{2}$ population were relatively small $(0-59 \mathrm{cM})$. Of the 51 linkage groups, only one was classified as a large linkage groups (Linkage group 1, having 40 markers covering a genetic distance of $169 \mathrm{cM}$; Table 4, Figure 2), while ten linkage groups had and intermediate size (each contains 6-21 markers, covering a genetic distance of 61 124 cM; Table; Figure 2). The other 40 linkage groups were relatively small (each contains 2 - 6 markers, covering a genetic distance of $0-59 \mathrm{cM}$ ). The prevalence of small linkage groups here may reflect the possible introgression of chromosomal segments from PI 494817 into the genomic background of Crimson Sweet, as was shown in other studies using $\mathrm{BC}_{2} \mathrm{~F}_{2}$ or $\mathrm{BC}_{3} \mathrm{~F}_{2}$ populations for the development of introgression lines $[25,31,38]$. 
Table 5. The linkage groups that were mapped in this study using the Testcross population. The linkage groups include high frequency oligoniclotide-targeting active gene (HFO-TAG) markers, , and targeted region amplification polymorphism (TRAP) markers, sequence related amplified polymorphism (SRAP) markers, amplified fragment length polymorphism (AFLP) markers, randomly amplified polymorphic DNA (RAPD) markers, and simple sequence repeat (SSR) markers. The total number of markers (TM) in each linkage group ranging from 2 to 40, and the genetic distance covered by each linkage group is ranging from 0 to169 $\mathrm{cM}$.

\begin{tabular}{|c|c|c|c|c|c|c|c|c|c|c|c|}
\hline Group & HFO & TRAP & SRAP & AFLP & RAPD & CLG/Cgb & ASUW & 1584 & TM & \multicolumn{2}{|c|}{ LG Distance } \\
\hline 1 & 0 & 4 & 10 & 50 & 11 & 0 & 0 & 0 & 75 & 174.1 & $\mathrm{cM}$ \\
\hline 2 & 20 & 8 & 7 & 4 & 17 & 0 & 0 & 0 & 56 & 203.3 & $\mathrm{cM}$ \\
\hline 3 & 0 & 6 & 8 & 4 & 18 & 1 & 0 & 0 & 37 & 87.8 & $\mathrm{cM}$ \\
\hline 4 & 5 & 2 & 3 & 4 & 7 & 0 & 0 & 0 & 21 & 109.6 & $\mathrm{cM}$ \\
\hline 5 & 0 & 7 & 13 & 2 & 13 & 3 & 1 & 0 & 39 & 104.6 & $\mathrm{cM}$ \\
\hline 6 & 1 & 3 & 7 & 5 & 11 & 0 & 0 & 0 & 27 & 98.7 & $\mathrm{cM}$ \\
\hline 7 & 0 & 0 & 3 & 0 & 3 & 0 & 0 & 0 & 6 & 62.4 & $\mathrm{cM}$ \\
\hline 8 & 1 & 1 & 2 & 0 & 1 & 0 & 0 & 0 & 5 & 61.9 & $\mathrm{cM}$ \\
\hline 9 & 9 & 6 & 6 & 10 & 30 & 0 & 0 & 0 & 61 & 240.1 & $\mathrm{cM}$ \\
\hline 10 & 5 & 3 & 6 & 2 & 24 & 0 & 0 & 0 & 40 & 130.8 & $\mathrm{cM}$ \\
\hline 11 & 1 & 4 & 11 & 0 & 20 & 1 & 0 & 0 & 37 & 209.2 & $\mathrm{cM}$ \\
\hline 12 & 3 & 3 & 4 & 3 & 13 & 1 & 0 & 0 & 27 & 102.3 & $\mathrm{cM}$ \\
\hline 13 & 0 & 0 & 3 & 0 & 4 & 1 & 2 & 1 & 11 & 79.5 & $\mathrm{cM}$ \\
\hline 14 & 2 & 0 & 2 & 1 & 5 & 0 & 0 & 0 & 10 & 84.7 & $\mathrm{cM}$ \\
\hline 15 & 0 & 0 & 3 & 0 & 6 & 0 & 0 & 0 & 9 & 88.9 & $\mathrm{cM}$ \\
\hline 16 & 0 & 1 & 3 & 1 & 1 & 0 & 0 & 0 & 6 & 92.8 & $\mathrm{cM}$ \\
\hline 17 & 0 & 1 & 2 & 0 & 0 & 2 & 0 & 0 & 5 & 55.8 & $\mathrm{cM}$ \\
\hline 18 & 2 & 2 & 0 & 0 & 1 & 0 & 0 & 0 & 5 & 20.5 & $\mathrm{cM}$ \\
\hline 19 & 0 & 0 & 0 & 2 & 0 & 0 & 2 & 0 & 4 & 20.0 & $\mathrm{cM}$ \\
\hline 20 & 3 & 3 & 3 & 0 & 4 & 1 & 1 & 0 & 15 & 91.3 & $\mathrm{cM}$ \\
\hline 21 & 3 & 1 & 2 & 1 & 1 & 0 & 0 & 0 & 8 & 89.6 & $\mathrm{cM}$ \\
\hline 22 & 0 & 1 & 4 & 1 & 0 & 0 & 0 & 0 & 6 & 75.9 & $\mathrm{cM}$ \\
\hline 23 & 0 & 2 & 2 & 0 & 0 & 0 & 0 & 0 & 4 & 47.0 & $\mathrm{cM}$ \\
\hline 24 & 0 & 0 & 1 & 0 & 2 & 0 & 0 & 0 & 3 & 41.0 & $\mathrm{cM}$ \\
\hline 25 & 0 & 0 & 2 & 0 & 0 & 0 & 0 & 0 & 2 & 35.3 & $\mathrm{cM}$ \\
\hline 26 & 0 & 0 & 3 & 0 & 0 & 0 & 0 & 0 & 3 & 33.9 & $\mathrm{cM}$ \\
\hline 27 & 0 & 0 & 0 & 2 & 0 & 0 & 0 & 0 & 2 & 32.8 & $\mathrm{cM}$ \\
\hline 28 & 0 & 0 & 0 & 2 & 0 & 0 & 0 & 0 & 2 & 21.9 & $\mathrm{cM}$ \\
\hline 29 & 0 & 0 & 1 & 0 & 1 & 0 & 0 & 0 & 2 & 19.9 & $\mathrm{cM}$ \\
\hline 30 & 0 & 0 & 0 & 2 & 0 & 0 & 0 & 0 & 2 & 12.9 & $\mathrm{cM}$ \\
\hline 31 & 0 & 0 & 2 & 0 & 0 & 0 & 0 & 0 & 2 & 14.2 & $\mathrm{cM}$ \\
\hline 32 & 0 & 0 & 0 & 2 & 0 & 0 & 0 & 0 & 2 & 38.3 & $\mathrm{cM}$ \\
\hline 33 & 0 & 0 & 0 & 1 & 3 & 0 & 0 & 0 & 4 & 38.4 & $\mathrm{cM}$ \\
\hline 34 & 0 & 0 & 2 & 0 & 0 & 0 & 0 & 0 & 2 & 33.3 & $\mathrm{cM}$ \\
\hline 35 & 0 & 0 & 1 & 3 & 0 & 0 & 0 & 0 & 4 & 22.0 & $\mathrm{cM}$ \\
\hline 36 & 2 & 0 & 0 & 0 & 0 & 0 & 0 & 0 & 2 & 20.6 & $\mathrm{cM}$ \\
\hline 37 & 1 & 0 & 0 & 0 & 1 & 0 & 0 & 0 & 2 & 19.6 & $\mathrm{cM}$ \\
\hline 38 & 0 & 0 & 2 & 0 & 0 & 0 & 0 & 0 & 2 & 18.7 & $\mathrm{cM}$ \\
\hline 39 & 0 & 2 & 1 & 0 & 1 & 0 & 0 & 0 & 4 & 17.0 & $\mathrm{cM}$ \\
\hline 40 & 0 & 0 & 2 & 0 & 0 & 0 & 0 & 0 & 2 & 5.9 & $\mathrm{cM}$ \\
\hline 41 & 0 & 0 & 0 & 2 & 0 & 0 & 0 & 0 & 2 & 4.4 & $\mathrm{cM}$ \\
\hline Total & 58 & 60 & 121 & 104 & 198 & 10 & 6 & 1 & 558 & 2760.8 & $\mathrm{cM}$ \\
\hline
\end{tabular}



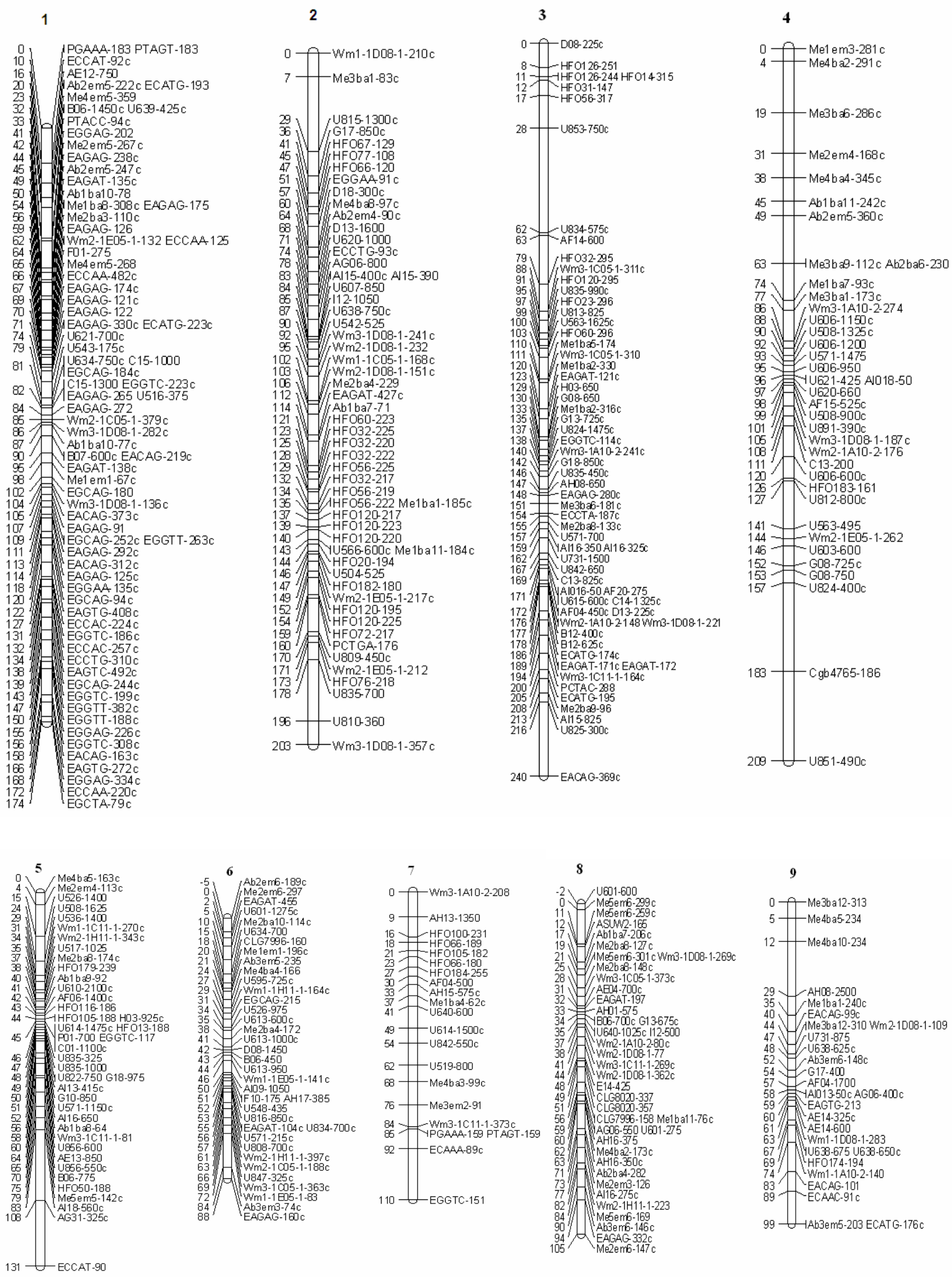


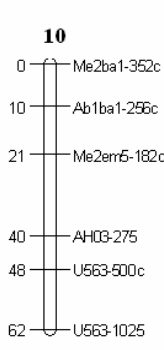

11

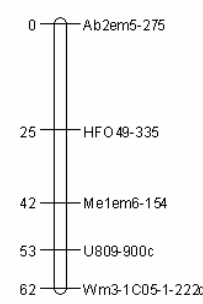

23

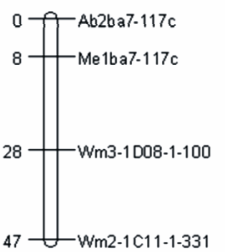

26

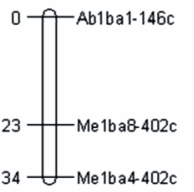

29

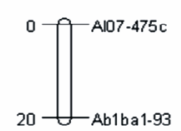

13

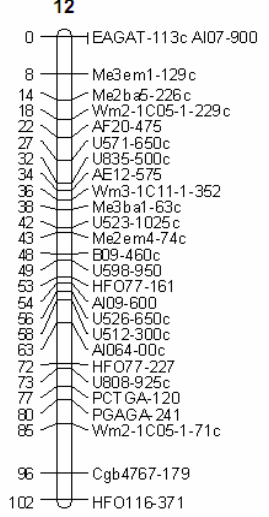

14

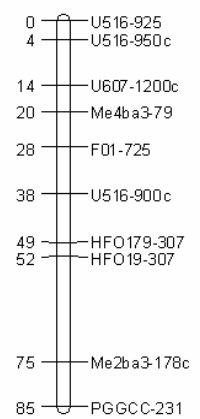

24

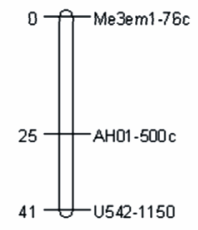

27

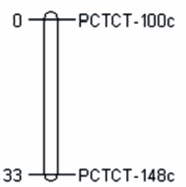

30

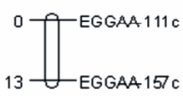

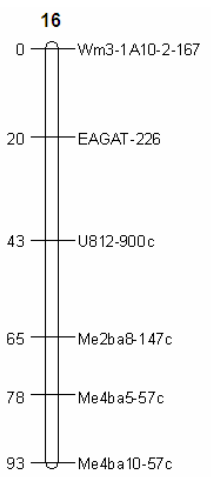
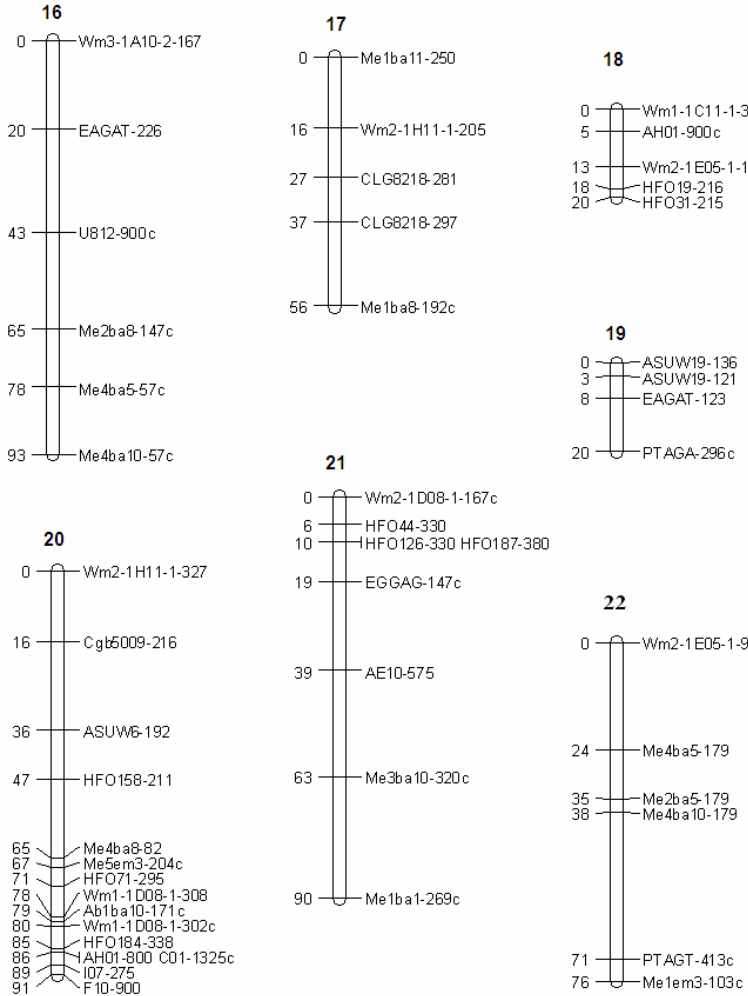

\begin{tabular}{r|r}
6 & HFO $44-330$ \\
10 & HFO $26-330$ HFO187-380
\end{tabular}

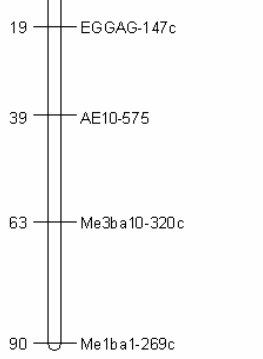

22

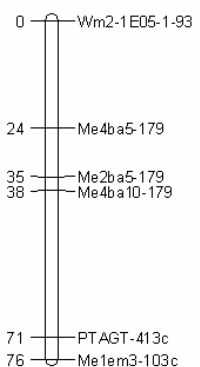

33

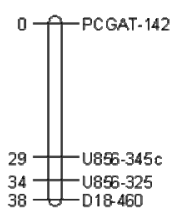

36

37
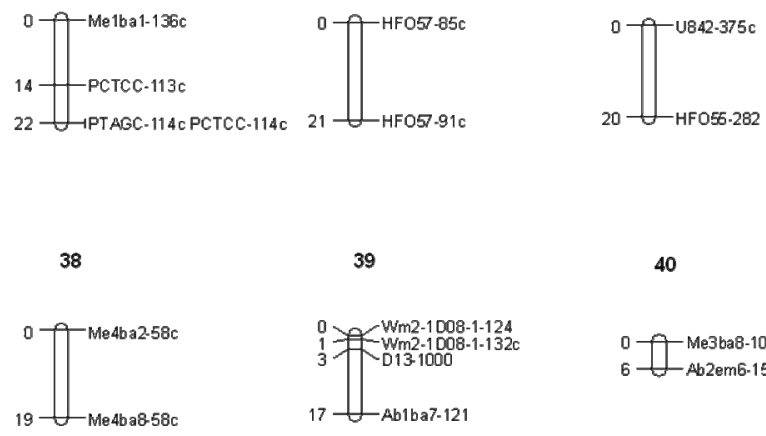

0 Me3ba8-104

41

Figure 3. An extended genetic linkage map for watermelon derived from a testcross population \{Griffin 14113 [C. lanatus var. citroide (L.H. Bailey) Mansf.] x watermelon cultivar New Hampshire Midget (C. lanatus var. lanatus)\} x PI 386015 [C. colocynthis (L.) Schrad.]. The map contains 41 linkage groups with 543 makers covering a genetic distance of $2100 \mathrm{~cm}$ with an average distance of $4.6 \mathrm{cM}$ between two markers. 
Of the 274 markers that were mapped here, 176 were from the donor parent PI 494817, while the other 98 markers were from the recurrent parent "Crimson Sweet". Most linkage groups contained markers representing one parent, but not the other. Linkage groups 2, 3, 4, 7, 9, 10, $12,17,20,21,22,23,24,25,26,28,31,33,34,35,37$, 40, 41, 45, 46, 49, 50 and 51 contained markers that represent the donor parent (PI 494817) only (Figure 2). On the other hand, linkage groups $5,8,11,13,14,15,16,18$, 19, 27, 29, 30, 32, 36, 38, 39, 42, 43, 47, and 48 contain markers that represent the recurrent parent (Crimson
Sweet) only (Figure 2). Linkage groups 1, 6, and 44 contain markers from both the donor and recurrent parent. The markers from the donor parent tended to group together, separated from those of the recurrent parent (as shown for linkage groups 1 and 6) (Figure 2). This clustering pattern, where markers from each individual parent tend to group unto themselves, indicates introgression of chromosomal segments from the donor into the recurrent parent (as indicated by Eshed and Zamir) [25,31].

Expanding the genetic linkage map based on a testcross population:
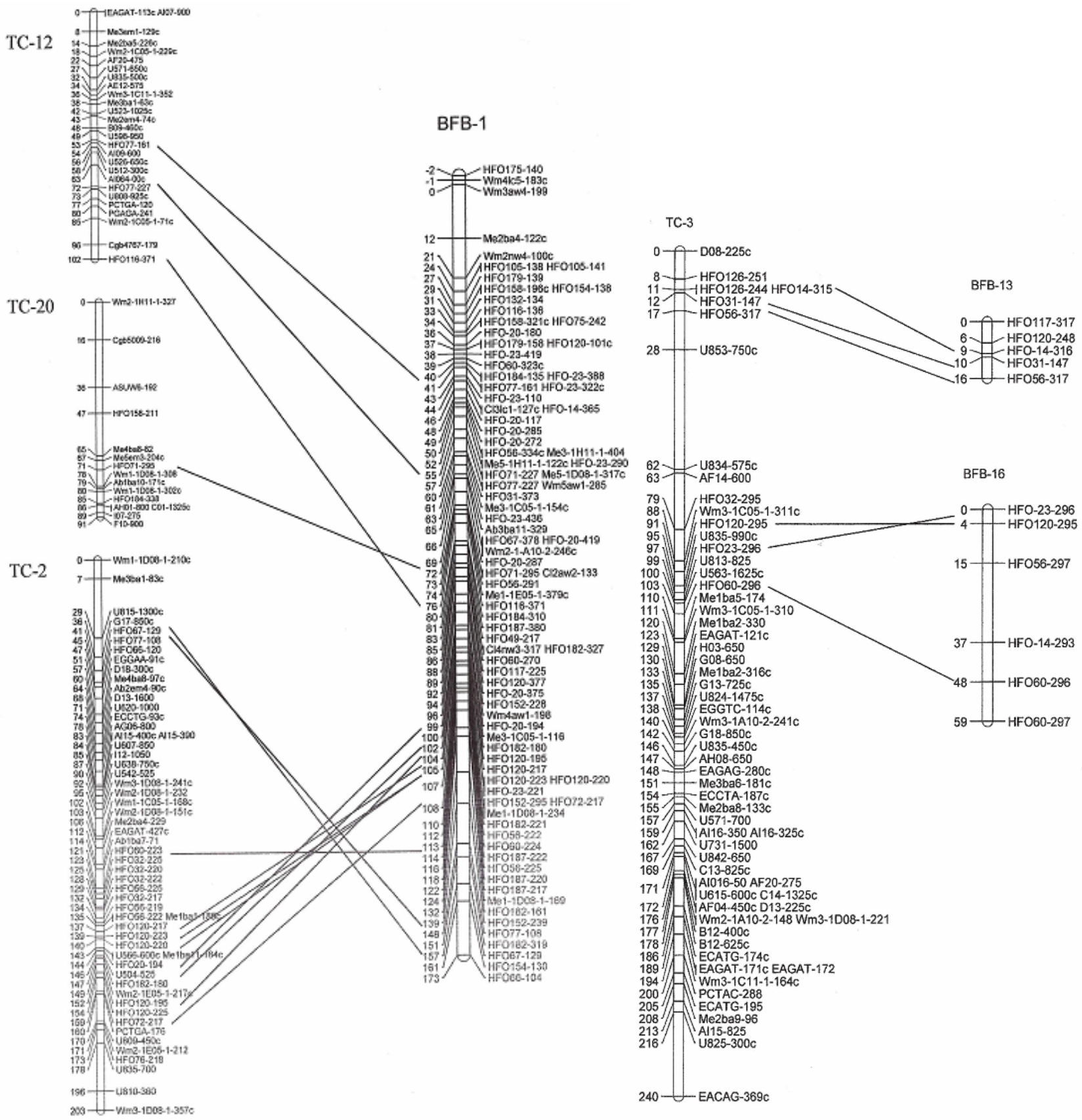

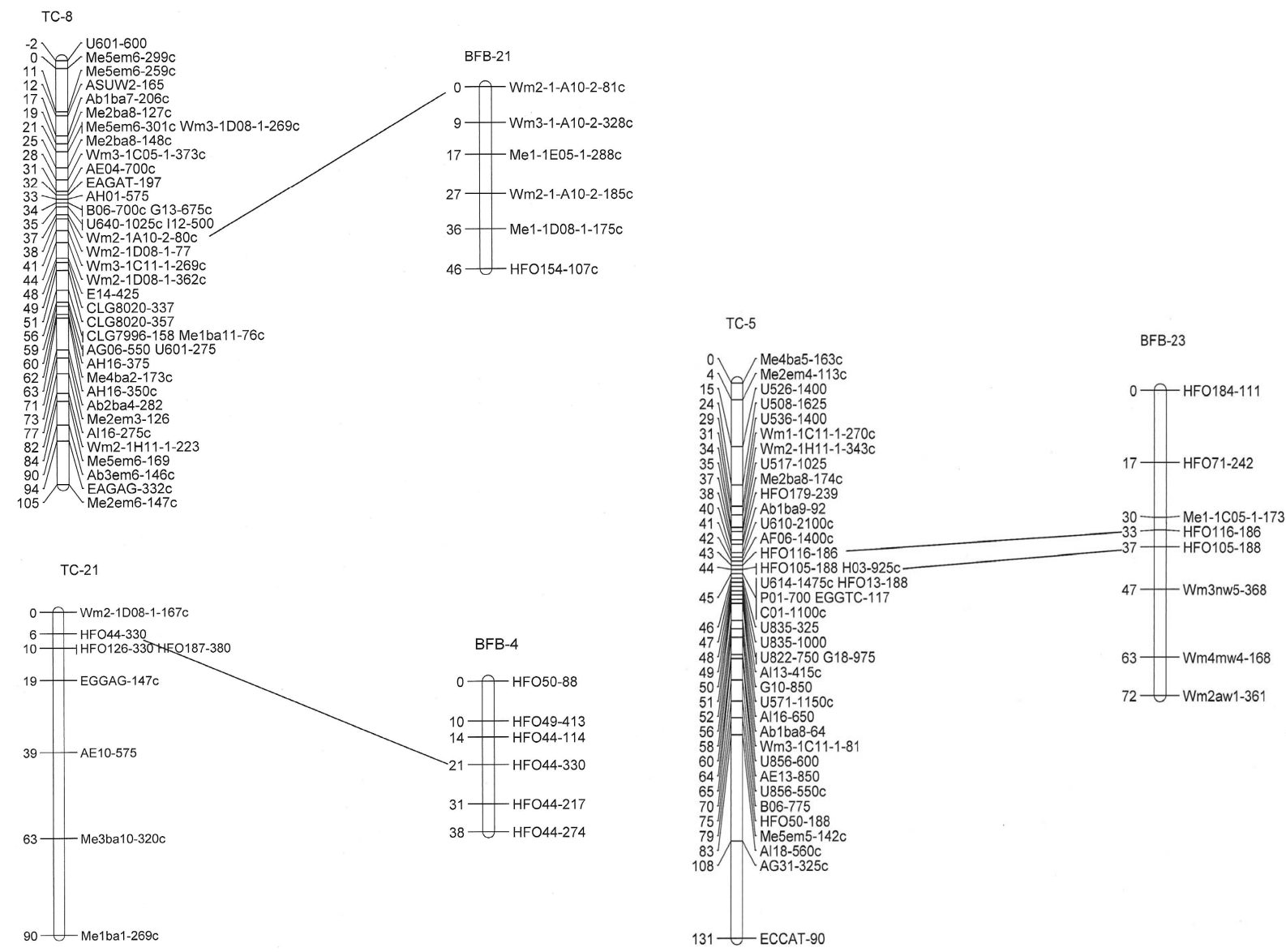

TC-10

BFB-2

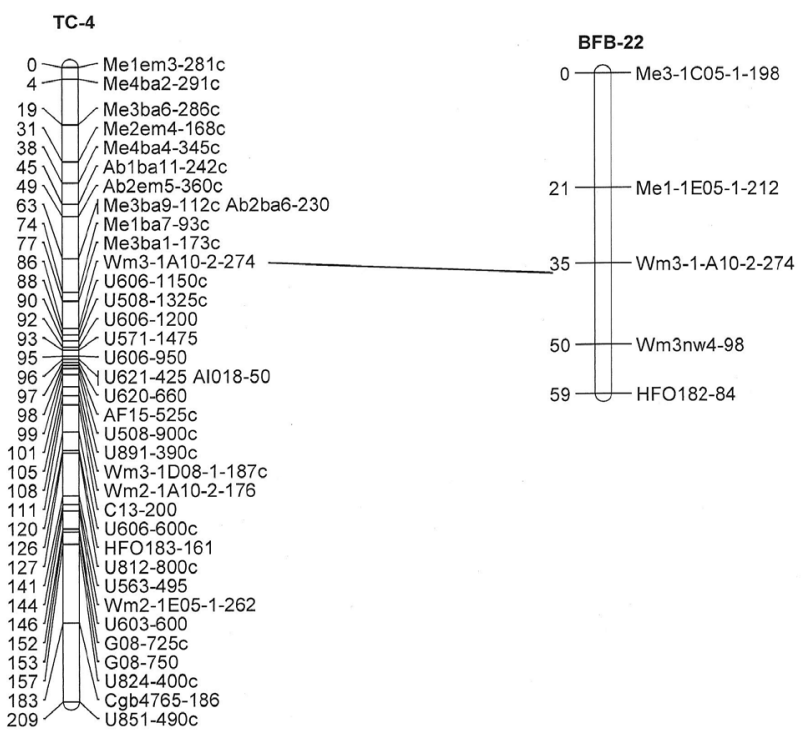

Figure 4. Comperative mapping between the linkage groups of the testcross map (Figure 3 ) and the $\mathrm{BC}_{2} \mathrm{~F}_{2}$ genetic map (Figure 2), showing consensus in marker genetic mapping.

The testcross population used in previous genetic mapping studies $[12,13,15,16]$ has been used here as a reference genetic map. Here the genetic linkage map was ex- panded from 363 DNA markers [13] to 558 DNA markers (Table 5, Figure 3). This linkage map consists of 41 linkage group, including 10 large linkage groups (rang- 
ing from102 - $240 \mathrm{cM}$ ), nine intermediate size linkage groups (ranging from $62-93 \mathrm{cM}$ ), and 22 small linkage groups (ranging from $2-56 \mathrm{cM}$ ). It should be noted that a relatively large genetic distance exists between markers among most of the small linkage groups (Table 5, Figure 3). Thus, the linkage groups may represent chromosomal regions with high recombination frequencies.

Comparative mapping between the testcross and the $\mathrm{BC}_{2} \mathrm{~F}_{2}$ genetic maps: The testcross and the $\mathrm{BC}_{2} \mathrm{~F}_{2}$ population are derived from different genotypes representing wide genotypic and phenotypic diversity [13]. Here, the analysis identified 26 markers shared between the genetic maps derived from the testcross and the $\mathrm{BC}_{2} \mathrm{~F}_{2}$ populations. These markers represent 9 linkage groups in the testcross and 8 linkage groups in the $\mathrm{BC}_{2} \mathrm{~F}_{2}$ map (Figure 4). It is notable that 25 of the 26 markers shared between the two linkage maps are HFO-TAG markers and one is a TRAP marker (Figure 4). These results indicate that the HFO-TAG markers which represent conserved regions associated with active genes [33] should be useful in comparative mapping using genetic populations derived from different genotypes.

There are several linkage maps for watermelon including a map based on an $\mathrm{F}_{2}$ population (both parents are cultivated accessions; $C$. lanatus var. lanatus), constructed by Hashizume et al. [39] in Japan, and a map based on a testcross population that consists of 363 DNA markers (including RAPD, AFLP, SRAP and SSR markers) [33]. Xu et al. [40] constructed a dense genetic linkage map for watermelon that consists mostly of SSR and EST-SSR markers. This map is derived from an $\mathrm{F}_{2} \mathrm{~S}_{8}$ recombinant inbred line (RIL) population of PI 296341 (C. lanatus var. citroides) x Chinese elite line 97103 (C. lanatus var. lanatus) [41]. Additional studies are needed to merge between the genetic maps constructed for watermelon.

Although our results with the advanced recombinant $\mathrm{BC}_{2} \mathrm{~F}_{2}$ population for identifying genes that confer moderate resistance to bacterial fruit blotch are not conclusive, this population should be useful for further development of introgression lines for watermelon. This $\mathrm{BC}_{2} \mathrm{~F}_{2}$ population should also prove useful for identifying and incorporating resistance genes that exist in wild watermelon $[15,16]$ into cultivated watermelon. Plant breeding programs for different crop plants have been using introgression lines for incorporating resistance genes from wild progenitors into cultivated types [38].

The linkage groups identified in this study should serve as a platform for further genetic mapping and development of introgression lines for watermelon. Several genetic populations $\left(\mathrm{BC}_{1} \mathrm{~F}_{2} ; \mathrm{BC}_{2} \mathrm{~F}_{2} ; \mathrm{BC}_{2} \mathrm{~F}_{2}\right.$ and $\left.\mathrm{BC}_{3} \mathrm{~F}_{3}\right)$ derived from a cross between PI 494817 and 'Crimson Sweet' were developed in this project. These populations are being used for further analysis and for development of introgression lines. These lines should be useful for expanding the narrow genetic base that exists among North American watermelon cultivars, and facilitate further analysis and identification of genes that confer disease resistance or control fruit quality in watermelon $[15,16,42]$.

\section{REFERENCES}

[1] D. M. Bates and R. W. Robinson, "Cucumbers Melon and Watermelons,” In: J. Smart and N. W. Simmonds, Eds., Evolution of Crop Plants, 2nd Edition, Longman, London, 1995, pp. 89-96.

[2] R. L. Jarret, L. C. Merrick, T. Holms, J. Evans and M. K. Aradhya, "Simple Sequence Repeats in Watermelon [Citrullus lanatus (Thunb.) Matsum \& Nakai],” Genome, Vol. 40, 1997, pp. 433-441. doi:10.1139/g97-058

[3] C. Mujaju, J. Sehic, G. Werlemark, L. Garkava-Gustavsson, M. Faith and H. Nybom, "Genetic Diversity in Watermelon (Citrullus lanatus) Landraces from Zimbabwe Revealed by RAPD and SSR Markers,” Hereditas, Vol. 147, No. 4, 2010, pp. 142-153. doi:10.1111/j.1601-5223.2010.02165.x

[4] A. Levi, C. E. Thomas, T. C. Wehner and X. Zhang, "Low Genetic Diversity Indicates the Need to Broaden the Genetic Base of Cultivated Watermelon," HortScience, Vol. 36, 2001, pp. 1096-1101.

[5] A. Levi, C. E. Thomas, A. P. Keinath and T. C. Wehner, "Genetic Diversity among Watermelon (Citrullus lanatus and Citrullus colocynthis) Accessions," Genetic Resources and Crop Evolution, Vol. 48, No. 6, 2001, pp. 559-566. doi:10.1023/A:1013888418442

[6] G. Gusmini, R. Song and T. C. Wehner, "New Sources of Resistance to Gummy Stem Blight in Watermelon," Crop Science, Vol. 45, No. 2, 2005, pp. 582-588. doi:10.2135/cropsci2005.0582

[7] R. D. Martyn and D. Netzer, "Resistance to Races 0, 1 and 2 of Fusarium Wilt of Watermelon in Citrullus sp. PI-296341-FR,” HortScience, Vol. 26, 1991, pp. 429-432.

[8] J. A. Thies and A. Levi, "Characterization of Watermelon (Citrullus lanatus var. citroides) Germplasm for Resistance to Root-Knot Nematodes,” Journal of Nematology, Vol. 42, 2007, pp. 1530-1533.

[9] A. Levi, C. E. Thomas, X. Zhang, T. Joobeur, R. A. Dean, T. C. Wehner and B. R. Carle, "A Genetic Linkage Map for Watermelon Based on Randomly Amplified Polymorphic DNA (RAPD) Markers," Journal of American Society for Horticultural Science, Vol. 126, 2001, pp. 730-737.

[10] L. K. Hawkins, F. Dane, T. L. Kubisiak, B. B. Rhodes and R. L. Jarret, "Linkage Mapping in a Watermelon Population Segregating for Fusarium Wilt Resistance,” Journal of American Society for Horticultural Science, Vol. 126, 2001, pp. 344-350.

[11] E. S. Buckler IV, T. L. Phelps-Durr, C. S. K. Buckler, R. 
K. Dawe, J. F. Doebley and T. P. Holtsford, "Meiotic Drive of Chromosomal Knobs Reshaped the Maize Genome,” Genetics, Vol.153, No. 1, 1999, pp. 415-426.

[12] A. Levi, C. E. Thomas, T. Joobeur, X. Zhang and A. Davis, “A Genetic Linkage Map for Watermelon Derived from a Testcross Population: (Citrullus lanatus var. citroides $\times$ C. lanatus var. lanatus $) \times$ C. colocynthis," Theoretical and Applied Genetics, Vol. 105, 2002, pp. 555-563.

[13] A. Levi, C. E. Thomas, T. Trebitsh, A. Salman, J. King, J. Karalius, M. Newman, O. U. K Reddy, Y. Xu and Z. Zhang, "An Extended Linkage Map for Watermelon Based on SRAP, AFLP, SSR, ISSR, and RAPD Markers," Journal of American Society for Horticultural Science, Vol. 131, 2006, pp. 393-402.

[14] J. Peng, A. B. Korol, T. Fahima, M. S. Röder, Y. I. Ronin, Y. C. Li and E. Nevo, "Molecular Genetic Maps in Wild Emmer Wheat, Triticum dicoccoides: Genome-Wide Coverage, Massive Negative Interference, and Putative Quasi-Linkage,” Genome Research, Vol. 10, 2000, pp. 1509-1531. doi:10.1101/gr.150300

[15] K. R. Harris, W. P. Wechter and A. Levi, "Isolation, Sequence Analysis, and Linkage Mapping of NBS-LRR Disease Resistance Gene Homologs in Watermelon," Journal of American Society for Horticultural Science, Vol. 134, 2009a, pp. 649-657.

[16] K. R. Harris, K. Ling, W. P. Wechter and A. Levi, “Identification and Utility of Markers Linked to the Zucchini Yellow Mosaic Virus Resistance Gene in Watermelon,” Journal of American Society for Horticultural Science, Vol. 134, 2009b, pp. 529-534.

[17] K. Ling, K. R. Harris, J. D. Meyer, A. Levi, N. Guner, T. C. Wehner, A. Bendahmane and M. J. Havey, "NonSynonymous Single Nucleotide Polymorphisms in the Watermelon eIF4E Gene Are Closely Associated with Resistance to Zucchini Yellow Mosaic Virus," Theoretical and Applied Genetics, Vol. 120, No. 1, 2009, pp. 191-200. doi:10.1007/s00122-009-1169-0

[18] D. L. Hopkins, "Bacterial Fruit Blotch of Watermelon: A New Disease in the Eastern USA,” In: C. E. Thomas, Ed., Proceedings Cucurbitaceae 1989: Evaluation and Enhancement of Cucurbit germplasm, U. S. Vegetable Laboratory, Charleston, 1989, pp. 74-75.

[19] G. C. Somodi, J. B. Jones, D. L. Hopkins, R. E. Stall, T. A. Kucharek, N. C. Hodge and J. C. Watterson, "Occurrence of a Bacterial Watermelon Fruit Blotch in Florida," Plant Disease, Vol. 75, 1991, pp. 1053-1056. doi:10.1094/PD-75-1053

[20] D. L. Hopkins, “Copper-Containing Fungicides Reduce the Spread of Bacterial Fruit Blotch of Watermelon in the Greenhouse,” Phytopathology, Vol. 85, 1995, p. 510.

[21] R. R. Walcott, A. Fessehaie and A. C. Castro, "Differences in Pathogenicity between Two Genetically Distinct Groups of Acidovorax avenae subsp. citrulli on Cucurbit Hosts,” Journal Phytopathology, Vol. 152, No. 5, 2004, pp. 277-285. doi:10.1111/j.1439-0434.2004.00841.x

[22] D. L. Hopkins and C. M. Thompson, "Evaluation of
Citrullus sp. Germplasm for Resistance to Acidovorax avenae subsp. Citrulli,” Plant Disease, Vol. 86, No. 1, 2002, pp. 61-64. doi:10.1094/PDIS.2002.86.1.61

[23] D. L. Hopkins and A. Levi, "Progress in the Development of Crimson Sweet-Type Watermelon Breeding Lines with Resistance to Acidovorax Avenae Subsp. Citrulli," Acta Horticulturae, In: M. Pitrat, Ed., Proceedings of the IX Eucarpia Meetings on Genetics and Breeding of Cucurbitaceae, INRA, 2008, pp.157-162.

[24] L. Inostroza1, A. del Pozo, I. Matus and P. Hayes, "Drought Tolerance in Recombinant Chromosome Substitution Lines (RCSLs) Derived from the Cross Hordeum vulgare subsp. spontaneum (Caesarea 26-24) $\times$ Hordeum vulgare subsp. vulgare CV. Harrington,” Agricultura Tecnican (Chile), Vol. 67, 2007, pp. 253-261.

[25] Y. Eshed and D. Zamir, “A Genomic Library of Lycopersicon pennellii in Lycopersicon esculentum-A Tool for Fine Mapping of Genes,” Euphytica, Vol. 79, No. 3, 1994, pp. 175-179. doi:10.1007/BF00022516

[26] Y. Eshed and D. Zamir, “An Introgression Line Population of Lycopersicon pennellii in the Cultivated Tomato Enables the Identification and Fine Mapping of YieldAssociated QTL," Genetics, Vol. 141, 1995, pp. 11471162.

[27] S. Tanksley, S. Grandillo, T. Fulton, D. Zamir, T. Eshed, V. Petiard, J. Lopez and B. T. Beck, “Advanced Backcross QTL Analysis in a Cross between an Elite Processing Line of Tomato and Its Wild Relative L. pimpinellifolium," Theoretical and Applied Genetics, Vol. 92, No. 2, 1996, pp. 213-224. doi:10.1007/BF00223378

[28] A. J. Monforte and S. D. Tanksley, "Development of a Set of Nearisogenic and Backcross Recombinant Inbred Lines Containing Most of the Lycopersicon hirsutum Genome in a L. esculentum Genetic Background: A Tool for Gene Mapping and Gene Discovery,” Genome, Vol. 43, 2000, pp. 803-813.

[29] M. J. W. Jeuken and P. Lindhout, "The Development of Lettuce Backcross Inbred Lines (BILs) for Exploitation of the Lactuca saligna (Wild Lettuce) Germplasm,” Theoretical Applied Genetics, Vol. 109, No. 2, 2004, pp. 394-401. doi:10.1007/s00122-004-1643-7

[30] S. Liu, R. Zhou, Y. Dong, P. Li and J. Jia, "Development, Utilization of Introgression Lines Using a Synthetic Wheat as Donor," Theoretical and Applied Genetics, Vol. 112, No. 7, 2006, pp. 1360-1373. doi:10.1007/s00122-006-0238-x

[31] V. C. Concibido, B. La Vallee, P. Mclaird, N. Pineda, J. Meyer, L. Hummel, J. Yang, K. Wu and X. Delannay, "Introgression of a Quantitative Trait Locus for Yield from Glycine soja into Commercial Soybean Cultivars," Theoretical Applied Genetics, Vol. 106, 2003, pp. 575582.

[32] L. D. Ramsay, D. E. Jennings, E. J. R. Bohuon, A. E. Arthur, D. J. Lydiate, M. J. Kearsey and D. F. Marshall, "The Construction of a Substitution Library of Recombinant Backcross Lines in Brassica oleracea for the Precision Mapping of Quantitative Trait Loci,” Genome, Vol. 39, No. 3, 1996, pp. 558-567. doi:10.1139/g96-071 
[33] A. Levi, W. P. Wechter, K. R. Harris-Shultz, A. R. Davis and Z. Fie, "High-Frequency Oligonucleotides in Watermelon Expressed Sequenced Tag-Unigenes are Useful in Producing Polymorphic Polymerase Chain Reaction Markers among Watermelon Genotypes,” Journal of American Society for Horticultural Science, Vol. 135, 2010, pp. 369-378.

[34] J. Hu and B. A. Vick, "Target Region Amplification Polymorphism: A Novel Marker Technique for Plant Genotyping,” Plant Molecular Biology Reporter, Vol. 21, No. 3, 2003, pp. 289-294. doi:10.1007/BF02772804

[35] A. Levi and C. E. Thomas, "An Improved Procedure for Isolation of High Quality DNA from Watermelon and Melon Leaves,” Cucurbit Genet Coop Report, Vol. 22, 1999, pp. 41-42.

[36] J. W. Van Ooijen and R. E. Voorrips, "JoinMap 3.0, Software for the Calculation of Genetic Linkage Maps," Plant Research International, Wageningen, 2001.

[37] Y. Z. Xing, W. J. Tang, W. Y. Xue, C. G. Xu and Q. Zhang, "Fine Mapping of a Major Quantitative Trait Loci, $q S S P 7$, Controlling the Number of Spikelets per Panicle as a Single Mendelian Factor in Rice," Theoretical and Applied Genetics, Vol. 116, No. 6, 2008, pp. 789-796. doi:10.1007/s00122-008-0711-9

[38] I. Schmalenbach, N. Korber and K. Pillen, "Selecting a Set of Wild Barley Introgression Lines and Verification of QTL Effects for Resistance to Powdery Mildew and Leaf Rust," Theoretical and Applied Genetics, Vol. 117, No. 7, 2008, pp. 1093-1106. doi:10.1007/s00122-008-0847-7

[39] T. Hashizume, I. Shimamoto and M. Hirai, "Construction of a Linkage Map and QTL Analysis of Horticultural Traits for Watermelon Citrullus lanatus (Thunb.) Matsum \& Nakai] Using RAPD, RFLP and ISSR Markers," Theoretical Applied Genetics, Vol. 106, No. 5, 2003, pp. 779-785.

[40] Y. Xu, S. Guo, H. Zhang, Y. Ren, H. Zhao, G. Lv, G. Gong, Z. Fei, Q. Kou, X. Zou, H. Wang and W. Hou, "International Watermelon Genomics Initiative (IWGI): Advance and Orientation,” In: J. Thies, A. Levi and C. Kousik, Eds., Cucurbitacaea 2010 Proceeding, Charleston, 2010.

[41] R. Zhang, Y. Xu, K. Yi, H. Zhang, L. Liu, G. Gong and A. Levi, "A Genetic Linkage Map for Watermelon Derived from Recombinant Inbred Lines," Journal of American Society for Horticultural Science, Vol. 129, 2004, pp. 237-243.

[42] A. Levi, A. Davis, A. Hernandez, P. Wechter, J. Thimmapuram, Y. Tadmor, N. Katzir, T. Trebitsh and S. King, "Genes Expressed during the Development and Ripening of Watermelon Fruit,” Plant Cell Report, Vol. 25, No. 11, 2006, pp. 1233-1245. 